\title{
Modeling of Hydraulically Controlled Exchange Flow in the Bosphorus Strait
}

\author{
Temel OGuz, Emin Özsoy, Mohammed A. Latif, Halil İ. Sur and Ümir ÜnlUata \\ Institute of Marine Sciences, Middle East Technical University, Erdemli-Içel, Turkey
}

(Manuscript received 5 May 1989, in final form 8 December 1989)

\begin{abstract}
Recent hydrographic observations obtained in the Bosphorus Strait illustrate several features of the flow that may be related with the internal hydraulics. A two-layer numerical model indicates that the two-way exchange flow may indeed be subject to a series of internal hydraulic adjustments along the strait due to morphological features such as sills, a contraction and abrupt expansion of the width of the strait. The model identifies three distinct regions of the supercritical flow. The lower-layer flow of the Marmara Sea origin is directed to the north towards the Black Sea in a progressively thinning layer and is controlled by the sill located near the Black Sea entrance of the strait. The upper-layer water of the Black Sea origin flows in the opposite direction and is controlled upon reaching the constricted region located about 10-12 km away from the Marmara end of the strait. The upper-layer flow is then matched to the subsequent subcritical conditions by undergoing an internal hydraulic jump and becomes subject to another critical transition near the abruptly widening exit section into the Marmara Sea. The controls exerted by the northern sill and the contraction are connected by a subcritical region whereas the supercritical conditions downstream of these controls isolate the two way exchange from the conditions in the adjacent regions. In this way, the requirement for the maximal exchange is met implying that the Bosphorus Strait achieves the maximum possible transports in the layers depending on the magnitude of net barotropic transport.
\end{abstract}

\section{Introduction}

The Bosphorus Strait constitutes a pathway between the Aegean and Black seas through the Sea of Marmara and the Dardanelles Strait (Figs. 1a,b). It is essentially a narrow, elongated and shallow channel of nearly 31 $\mathrm{km}$ length. The width varies between 0.7 and $3.5 \mathrm{~km}$ with an average value of $1.3 \mathrm{~km}$ at the surface. The width reduces gradually towards the bottom of the channel to a typical average value of $500 \mathrm{~m}$ at a depth of $50 \mathrm{~m}$. The depth varies in the range of 30 and 100 $\mathrm{m}$. Significant cross-channel variations make it difficult to assign an average depth for a given cross section. An approximate value of $50 \mathrm{~m}$ may, however, be considered a representative average depth along the central section of the channel.

The Bosphorus Strait exhibits distinguished geometrical features associated with its width and depth variations. The constricted region found at about 10$12 \mathrm{~km}$ from its Marmara extremity, two sills located to the south of the constriction and immediately outside its northern exit to the Black Sea as well as the abrupt termination of the channel at the southern end are the elements of the Bosphorus morphological structure influencing the ultimate form of the flow. The constricted region starts at the Emirgan-Kanlica

Corresponding author address: Dr. Temel Ogŭz, Institute of Marine Sciences, Middle East Technical University, P.O. Box 28, ErdemliIcel, Turkey. section and continues to the south near the Arnavutkoy-Vanikoy section comprising a length of approximately $2.5 \mathrm{~km}$ with the narrowest section of about 500 m (Fig. 1b).

The sill, situated to the south of the constricted region, extends along the midchannel with a minimum depth of about $28 \mathrm{~m}$ between two narrow and deeper channels located on both sides (Fig. 2). On the Anatolian side of the sill, along the Ussküdar coast, the channel having a depth of about $40 \mathrm{~m}$ is also blocked off downstream by a shallower area with a sill depth of $33 \mathrm{~m}$. This channel gradually deepens beyond the sill towards the south and eventually joins the submarine canyon found in the junction region of the Bosphorus and the Marmara Sea. The northern sill has a minimum depth of about $59 \mathrm{~m}$ and a length of about $3 \mathrm{~km}$ (Fig. 1b). It lies within a narrow channel, generally known as the pre-Bosphorus channel, which forms a natural extension of the strait into the Black Sea. The exact location of the sill and the details of the bathymetrical characteristics of the region surrounding the Bosphorus-Black Sea junction have been established by recent field studies (Latif et al. 1990).

The Bosphorus Strait possesses a well-defined two layer stratification and associated a two-layer system of exchange. The southward barotropic flow is driven by the sea level difference between its two ends which varies, on the average, in the range of $20-40 \mathrm{~cm}$, with small tidal oscillations of the order of $10 \mathrm{~cm}$ (Gunnerson and Özturgut 1974; De Filippi et al. 1986; Bü- 
yükay 1989). The northward baroclinic flow, on the other hand, is driven by the difference in density (which is predominantly governed by the salinity) between the Marmara and the Black seas. Consequently, relatively fresh water of the Black Sea flows towards the Sea of Marmara on top of the oppositely flowing more saline and denser water of the Mediterranean Sea origin. On the basis of historical data, salient aspects of its oceanographical characteristics have been described earlier by Ünlüata and Og̈uz (1983) and Tolmazin (1985) and the references cited therein. In conjunction with a program for establishing the state of health and oceanography of the Turkish straits, mixing, stratification and flow characteristics of the Bosphorus Strait as well as its junction regions with the Marmara and Black seas have recently been studied extensively in the hydrographic surveys with a closely spaced station network (see Figs. 1b,c for the Bosphorus stations). The results of these investigations related with the regional physical oceanographic characteristics have been described in a series of reports (Özsoy et al. 1986, 1988; Latif et al. 1988) and reviewed by Ünlüata et al. (1990).

One of the interesting characteristics of the Bosphorus Strait, emerging from the hydrographic surveys, is the presence of some persistent features which may apparently be related with multiple hydraulic controls on the flow (see section 2). It is known that the horizontal and vertical constrictions as well as abrupt expansions in channel bathymetries may exert efficient controls on the flow in a channel between two deep reservoirs. The best known example of controlled flow conditions is the Strait of Gibraltar as described recently by Armi and Farmer (1988) or Farmer and Armi (1988), and La Violette and Arnone (1988). Further examples of flows subjected to the internal hydraulic conditions have been dealt with Farmer and Denton (1985), Stacey and Zedel (1986), Wang (1987), Stigebrant (1981). The presence of internal hydraulic adjustment of the flow are inferred in the hydrographic transects by prominent asymmetries and rapid transitions of the interface depth as well as the locations of intense vertical mixing associated with the internal hydraulic jumps.

A theoretical analysis of internal hydraulics for a steady, frictionless, immiscible, two-layer flow through a channel between two deep and homogeneous basins has been given by Farmer and Armi (1986), Armi and Farmer (1987). Specifically, Farmer and Armi (1986) describe how a sill and contraction (or abrupt expansion of the channel width) found at its two ends act together to constrain the exchange flow and consequently lead to the conditions of maximal exchange between the basins. In this way, the supercritical conditions on either side of the control sections isolate the two-layer exchange in the channel from the conditions in the adjacent basins. Depending on the average densities of the layers, the channel geometry and the magnitude of the net barotropic flow passing through the channel, the critical controls determine the magnitudes of flows in the layers and the shape of the interface.

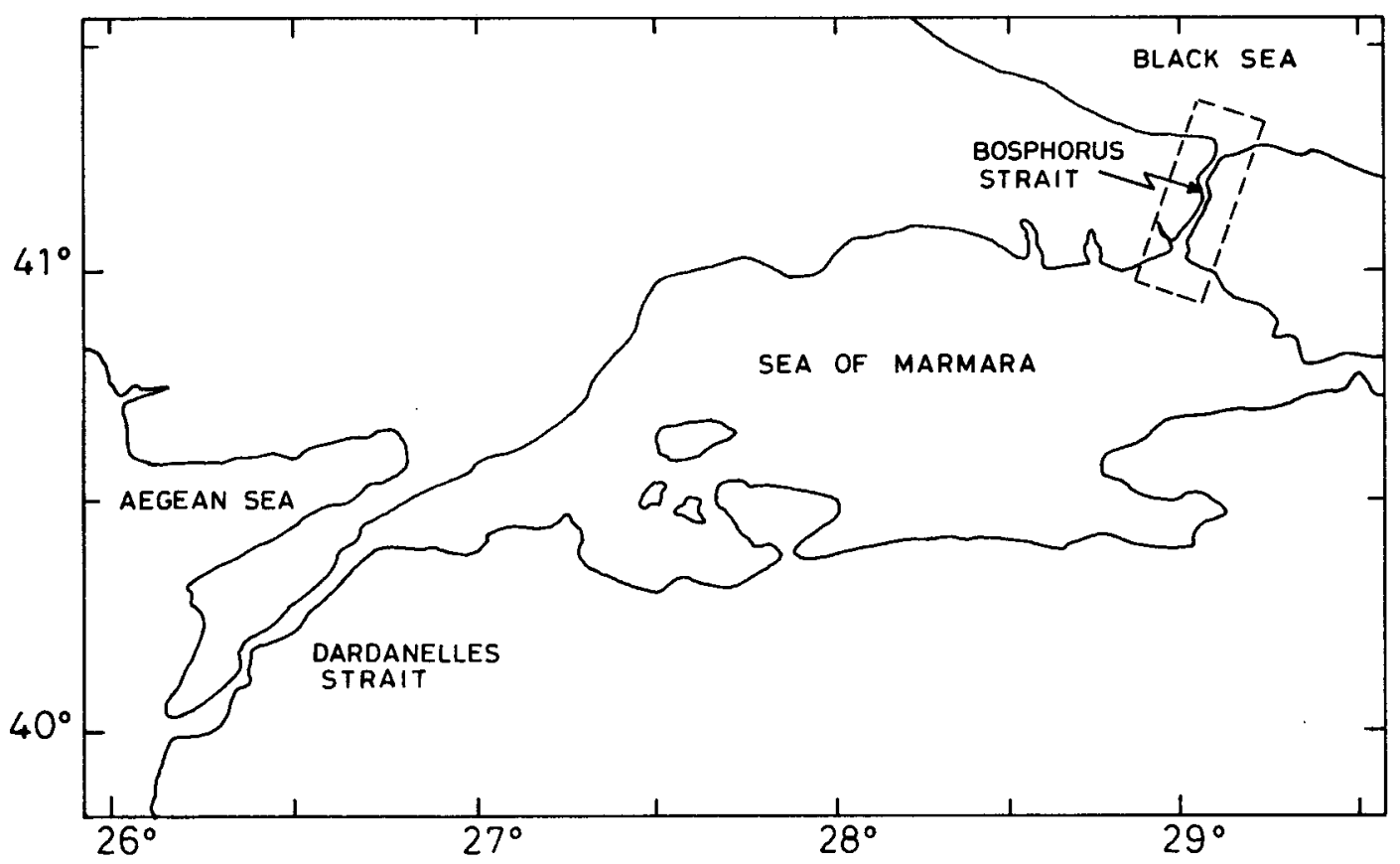

FIG. 1a. The location map for the components of the Turkish Strait System with the rectangular box showing the region under consideration in the present study. 


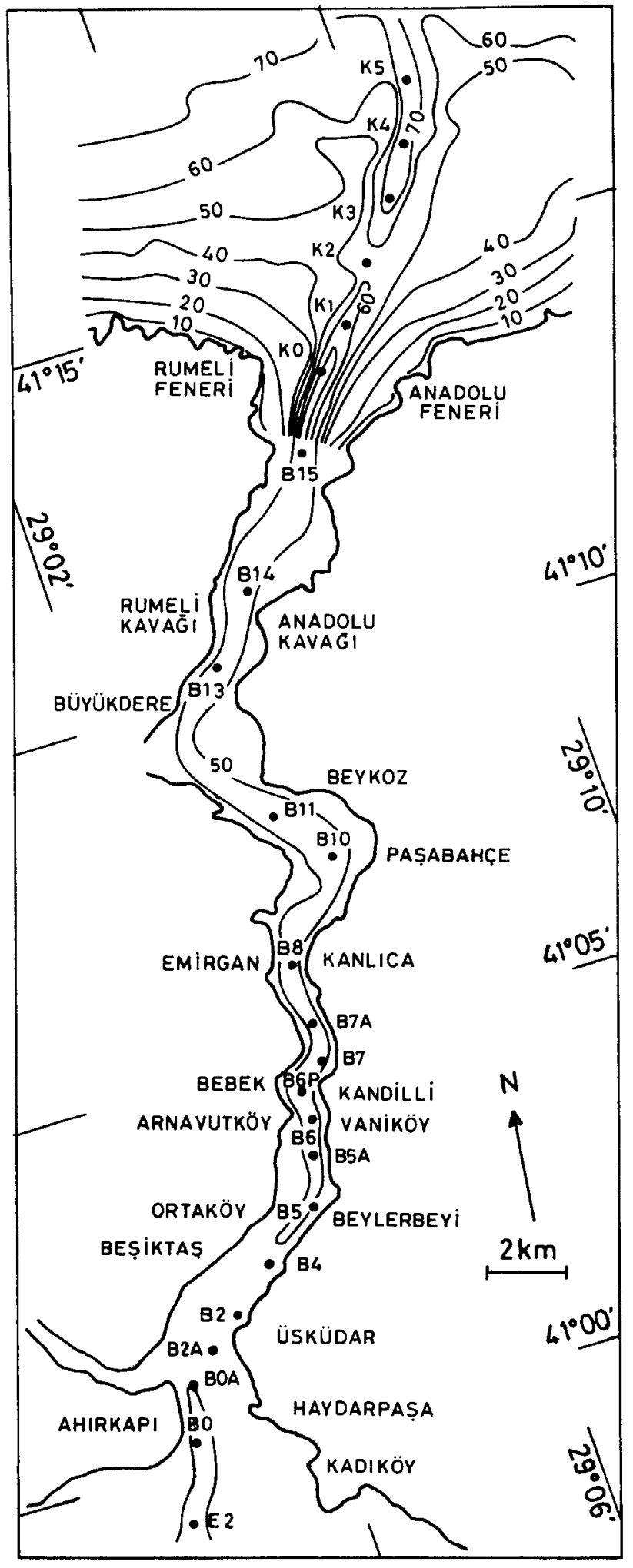

FIG. 1b. Plan view of the Bosphorus geometry and locations of the hydrographic stations.

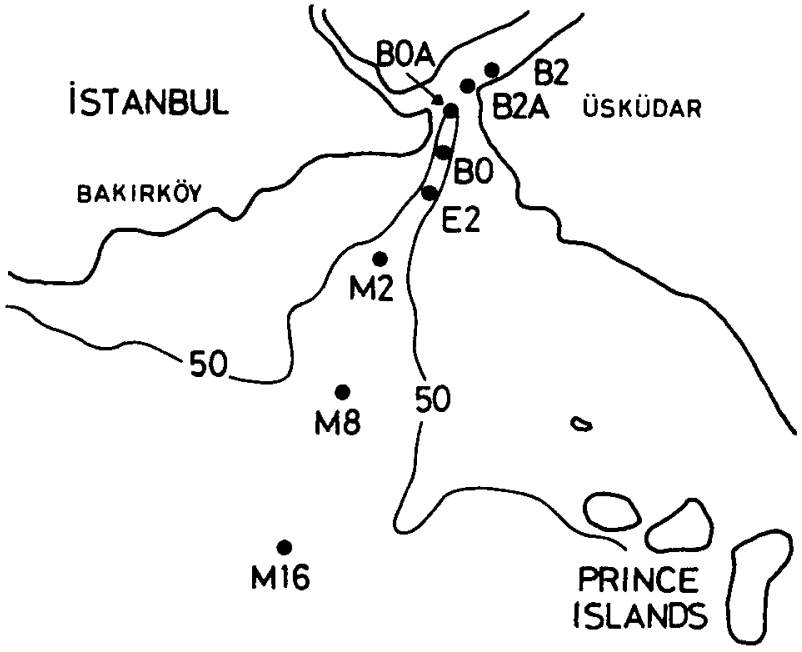

FIG. Ic. Plan view of the Marmara exit region of the Bosphorus Strait and locations of the hydrographic stations referred to in the text.

The two-layer models reported by Assaf and Hecht (1974) and Sümer and Bakioğlu ( 1981) also deal with steady, immiscible flows possessing critical controls at the exit sections of an idealized channel. They additionally include frictional processes at the interface and the bottom, and may therefore be regarded as the ex-

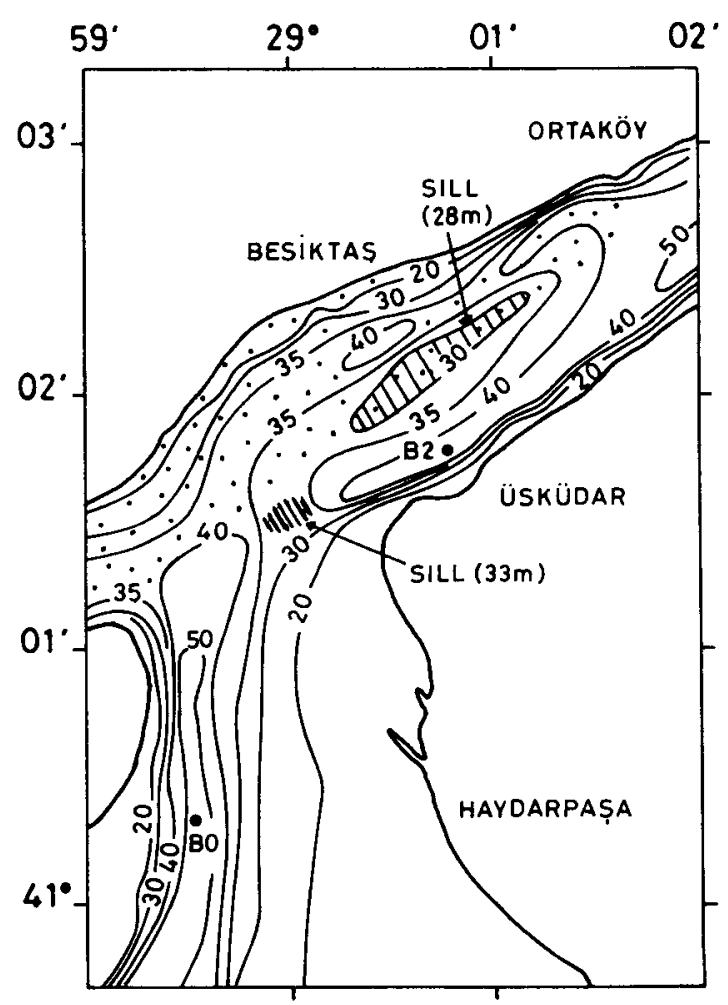

FIG. 2. Bathymetry of the southern exit region of the Bosphorus Strait. 
tension of the maximal exchange concept given in Farmer and Armi (1986) to the cases in which frictional effects modify the exchange through a long strait. The essential points of the model formulations and the principal results are reviewed by Tolmazin (1985) and Özsoy et al. (1986).

Ceçen et al. (1981) studied the dynamics of the Bosphorus exchange flow by a two-layer, steady, frictional, nonlinear model. It incorporates the realistic width and depth variations and includes the effects of alongchannel salinity variations as well as the entrainment mechanism across the interface. The model is based on numerical iterative solutions of the continuity, horizontal momentum and salt transport equations for the layers. The calculations start with prescribed critical condition at a known control section specified at the minimum cross-sectional area near the Marmara end of the Strait, and progress towards the Marmara and Black Sea extremities of the strait to determine the layer-averaged currents and salinities as well as the layer thicknesses. In this respect, the model is similar to the simulation of a salinity intrusion in the Mississippi River described by Balloffet and Borah (1985). The model is however extended only up to the northern exit of the Strait into the Black Sea. It therefore can not predict the internal hydraulic control exercised by the northern sill and consequently is not able to describe the maximal exchange in the Bosphorus Strait.

The present paper describes a numerical model to explain the anticipated hydraulically controlled exchange mechanism in the Bosphorus Strait. A two-layer model appears to be adequate for this purpose and is considered to provide a satisfactory explanation for most of the observed flow features. As opposed to earlier models, the present model simulates the nature of the exchange (whether maximal or submaximal) by determining the locations of the internal hydraulic transitions of the flow in terms of certain external parameters, such as the densities at the adjacent basins, the magnitude of the net barotropic flow and specification of the along-channel depth and width variations. The model incorporates mixing, frictional effects and time dependent features which, as pointed out by Armi and Farmer $(1987,1988)$, are indeed important aspects of the maximal exchange.

The paper is organized as follows: a brief description of the observed hydrographic characteristics related with its internal hydraulics is described in section 2 . Model formulation and various numerical experiments carried out with the model are discussed in sections 3 and 4 , respectively. The summary and conclusions are presented in section 5 .

\section{Hydrographic characteristics related with the in- ternal hydraulics}

The two-layer stratification and associated flow structure in the Bosphorus have marked temporal variations. The seasonal variations depend particularly on the intensity of the Black Sea inflow at the surface layer and are dominated frequently by shorter term changes (on the order of few days) occurring in response to prevailing wind conditions. The two-layer stable density stratification is controlled by the salinity, and the temperature stratification is relatively unimportant. In winter months, the flow regime is characterized by cooler waters of Black Sea origin ( minimum of about $4^{\circ}-5^{\circ} \mathrm{C}$ ) above relatively warmer Mediterranean waters $\left(14^{\circ}-15^{\circ} \mathrm{C}\right)$. A different temperature structure is formed during summer months with relatively warmer surface layer waters and cold subsurface waters located above the transitional layer, overlying the lower-layer Mediterranean waters. The temperature near the surface may reach $24^{\circ} \mathrm{C}$, whereas an inversion layer of cold subsurface Black Sea waters, unaffected by radiational heating, attains typical temperatures of about $9^{\circ}-10^{\circ} \mathrm{C}$. The salinity of the upper layer varies between $16.5-18.5 \mathrm{ppt}$ in the northern half of the strait through the year, with lower values indicating summer conditions corresponding to the increased Black Sea inflow. The salinity of the lower layer waters attains a maximum value of $38.5 \mathrm{ppt}$ near the Marmara end of the strait, and decreases progressively towards the northern exit at a rate depending on the intensity of vertical mixing.

The typical variations, both temporal and spatial, taking place in the Bosphorus Strait are delineated by the salinity transects shown in Figs. 3a-e. In these transects, the typical flow conditions in the Bosphorus with some seasonal variations are displayed in Fig. 3c. The cases with increased upper layer flow as responses to pronounced northerly winds from the Black Sea are shown in Figs. 3a,b. The opposite case of increased (reduced) lower (upper) layer flow as a result of southerly winds from the Marmara Sea are presented in Figs. 3d,e. The strait and its adjacent junction regions are covered by fine resolution CTD data both in the vertical $(\sim 1 \mathrm{~m})$ and in the horizontal $(\sim 1-2 \mathrm{~km})$ obtained by means of the SeaBird SBE 9 profiling instrument. The stations shown in the transects correspond to deepest locations of the cross sections and are completed in approximately $6 \mathrm{~h}$ (see Figs. 1b,c for the locations of stations).

As may be noted in Fig. 3c, the interface may generally be identified by a transitional layer between the salinity limits of $18-23$ and 33-38 ppt. It is relatively sharper at the northern part of the strait with an average thickness of about $5 \mathrm{~m}$ located at the depths of $40-50$ $\mathrm{m}$. It extends with a mild slope towards the southern part where significant changes take place with respect to its position and stratification characteristics. The region to the south of the constricted region is characterized by intense vertical mixing, pronounced nonlinear variations of the interface and the intensification of the upper layer currents. The vertical mixing results in a total increase of about $3 \mathrm{ppt}$ in the upper layer 
salinity between the two ends of the strait. Towards the southern end, the interfacial layer becomes much thicker and attains a thickness of 10-15 m, above which the surface layer flow eventually joins the Marmara exit region in the form of a shallow, turbulent buoyant jet. The surface layer has a thickness of 10-15 $\mathrm{m}$ and salinities of 21-22 ppt at the southern exit region. The lower layer waters enter the strait below a depth of about $25 \mathrm{~m}$, and proceed northward by flowing over the sill. Most of the mixing takes place in the region to the south of the narrowest section (to the south of B7). Thereafter, the rate of vertical mixing is insignificant and the Mediterranean effluent joins the pre-Bosphorus channel with the maximum salinity of $36.5 \mathrm{ppt}$ below a depth of $50 \mathrm{~m}$.

Figure $3 \mathrm{~b}$ displays similar conditions with somewhat stronger flows entering into the strait from both ends. Consequently, the interface is relatively thinner and sharper and therefore the interfacial mixing is less pronounced as compared to the previous case. The underflow passes over the northern sill with a salinity of $37.5 \mathrm{ppt}$ and thickness of $6-8 \mathrm{~m}$ before joining the shelf as a dense gravity flow.

Figure $3 \mathrm{a}$ reflects an extreme case of large upperlayer inflow from the Black Sea due to high northerly winds prevailing over the region in the last few days preceeding the survey. In this distinctly different case, the interface is located below a very deep, wind-induced mixed layer reaching depths of $60-65 \mathrm{~m}$ at the Black Sea extremity, and extending almost horizontally up to the constricted region. As compared to the cases shown in Figs. 3b,c, where the outflow of Mediterranean waters into the Black Sea was always insured, the high rate of surface-layer inflow caused almost complete blocking of the underflow below the northern sill level. The maximum salinity measured just above the sill is about $25 \mathrm{ppt}$ whereas it attains values of $36 \mathrm{ppt}$ at the deepest level immediately upstream of the sill. In the southern half, the conditions are, however, quite different as characterized by considerable vertical mixing of lower layer waters with the upper layer. The shape of isohalines implies that the lower layer inflow may only be advected partially towards north and returns partially back to the Marmara Sea. It is noted that the underflow with salinity greater than $33 \mathrm{ppt}$ is an extremely thin layer downstream of the southern sill.

Figures 3d,e denote to cases with higher rate of vertical mixing due to the intensified lower layer inflow, and weakened upper layer flow caused by the southerly winds. The transitional layer becomes relatively thick throughout the strait as compared with the much stronger interfacial contrast observed in the case of intense upper layer flow conditions. In the case of 31 August 1989 survey (Fig. 3e) carried out one day after a strong southerly wind episode, the two layer stratification is hardly seen, and the features observed in the earlier transects have changed substantially.
Except for the extreme case presented in Fig. 3e, all of the transects reveal some common features that may be associated with the internal hydraulics. In particular, as the upper layer flow passes through the constricted region, rapid changes are indicated at the position of the interface. The maximum changes occur exactly between stations B6 and B7 located close to each other. Here the interface slopes sharply upwards by about $10-25 \mathrm{~m}$, suggesting possibly that the flow adjusts itself to the critical hydraulic condition and becomes supercritical immediately to the south of the control section. Thereafter, the sharp rise of the interface comes to an abrupt end, and the interface depth deepens to a position which would be normally attained in the absence of controlled flow conditions. The upper layer flow thus adjusts itself to the subcritical state by undergoing an internal hydraulic jump. Increased separation of isohalines both within each layer and at the interfacial zone observed to the south of the control section implies increased vertical mixing in the supercritical regime of the upper layer flow and the subsequent internal hydraulic jump.

Following the controlled flow conditions at the constriction region, rapid changes occur again in the shape of isohalines suggesting the presence of a second controlled flow situation near the southern end of the strait. The region between the southern sill and the Besiktas coast actually consists of a clockwise recirculation zone in the surface layer extending farther south up to the entrance of the Golden Horn estuary (see dotted region in Fig. 2). The southerly flowing mainstream is therefore confined primarily into a narrow channel having depths of about $40 \mathrm{~m}$ on the opposite (Üsküdar) side of the sill. Consequently, the upper layer flow accelerates in passing through the region and may be subject to internal hydraulic adjustment at this section of the strait as well as in the subsequent abruptly widening exit section into the Marmara Sea. These potential controls are, in fact, so close to each other that if the flow is controlled in the sill region and becomes supercritical to the south, it may continue to be in the supercritical regime up to the Marmara exit region of the strait. In any case, their influences on the exchange flow can not be distinctly separated in the hydrographic transects, which generally show sharp and continuous rise of isohalines to the south of station $\mathrm{B} 5$ up to stations B0 and E2 in Figs. 3a-d. The strongest mixing is, however, seen at the exit region into the Marmara Sea (between stations B0 and M2). It may therefore be inferred that a second internal hydraulic jump takes place in the vicinity of station $\mathrm{M} 2$ for the transition of the controlled flow to the equilibrium two-layer subcritical conditions of the Sea of Marmara.

Turning our attention to the lower layer waters of the Mediterranean origin, it is seen that the dense water having salinities of about $38 \mathrm{ppt}$ flows towards the north in a progressively thinner layer. After it passes over the southern sill, it appears that a hydraulic jump or finite 


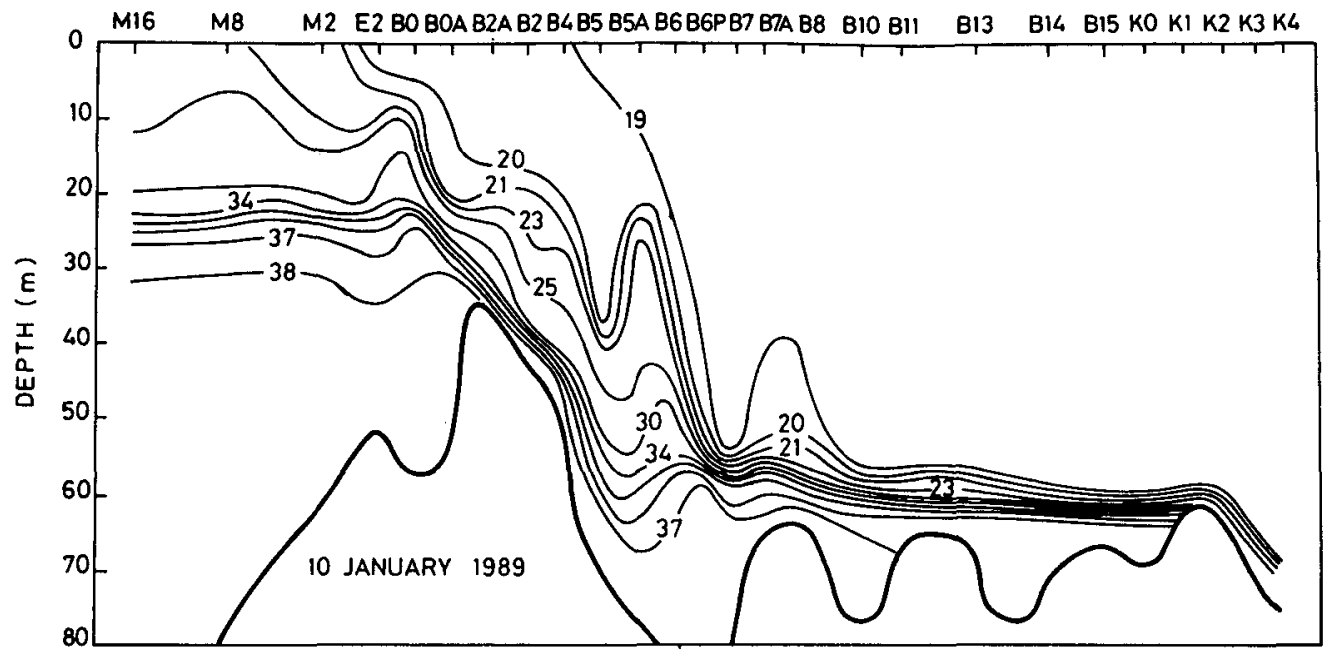

FIG. 3a. Salinity transect in the Bosphorus Strait for January 1989.

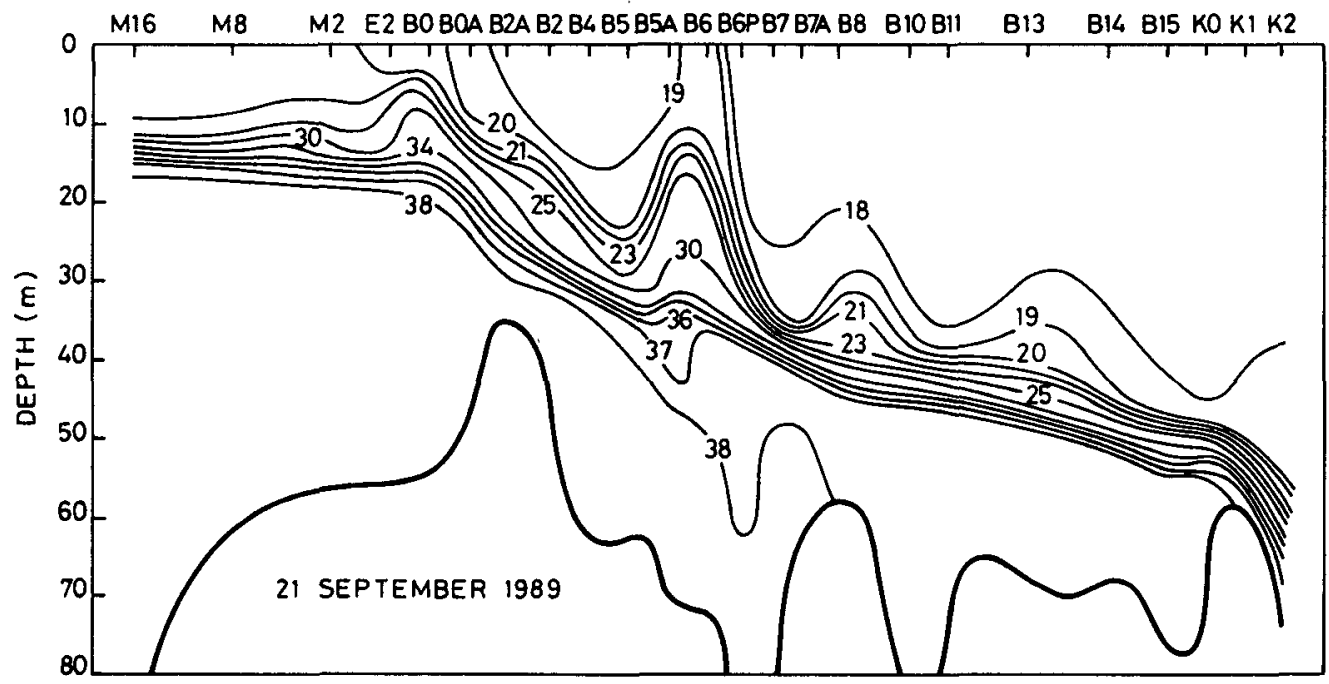

FIG. 3b. Salinity transect in the Bosphorus Strait for September 1989.

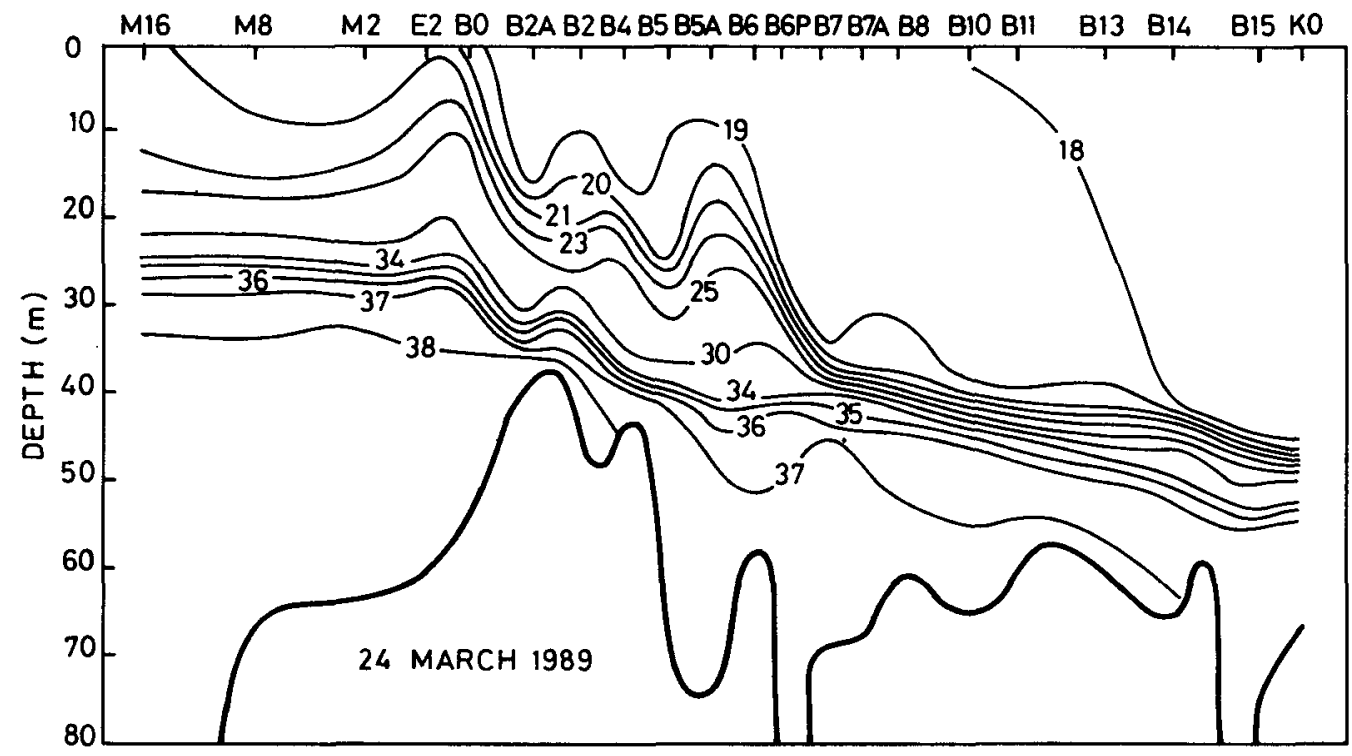

FIG. 3c. Salinity transect in the Bosphorus Strait for March 1989. 


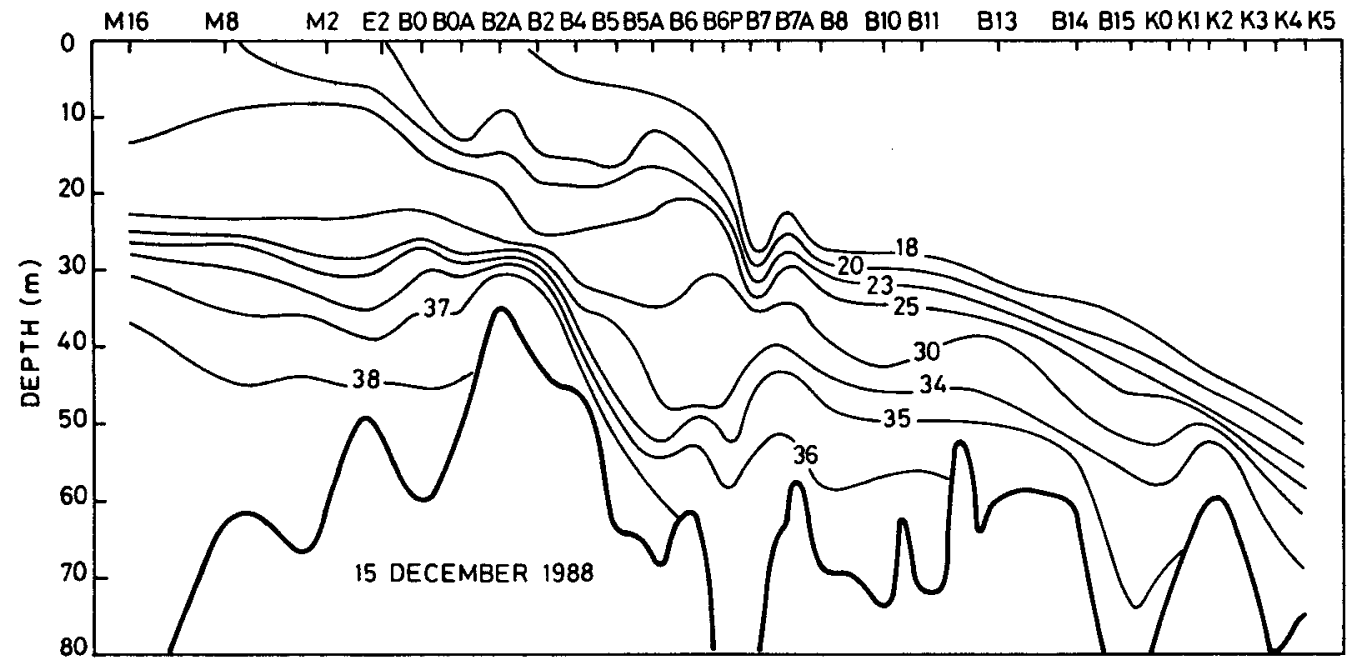

FIG. 3d. Salinity transect in the Bosphorus Strait for December 1988.

amplitude lee wave forms at the downstream side of the sill depending on the intensity of the underflow and the thickness of the layer (Farmer and Freeland 1983). This feature is identified by the diffusive forms of the isohalines within the lower layer near stations B5-B5A. Upon reaching the northern exit region, the underflow enters the Black Sea by accelerating over the sill in the form of a thin plume having an average thickness of about $10 \mathrm{~m}$. The form of isohalines (see Fig. 3e) implies the presence of an internal hydraulic adjustment of the lower-layer flow at the sill. The Mediterranean effluent flowing downhill in the form of a density current soon reverts to the subcritical conditions of the western Black Sea by undergoing an internal hydraulic jump. In fact, the position of the main halocline in the western Black Sea shelf region, typically situated at levels deeper than the sill depth $(\sim 100 \mathrm{~m})$ (cf. Ogguz et al. 1990), makes necessary the internal hydraulic adjustment of the underflow as mathematically shown by Pratt (1986).

It should be stressed that this interpretation of Bosphorus internal hydraulics is only qualitative and solely based on the hydrographic measurements. Unfortunately, velocity measurements are not available at the present to support the CTD measurements for establishing definitely the nature of the exchange taking place in the Bosphorus.

From the foregoing discussion, it is seen that the basic mechanism of the hypothetical internal hydraulics in some generality satisfies the requirement of the maximal exchange in the Bosphorus by the controls imposed at the northern sill and the constriction, which

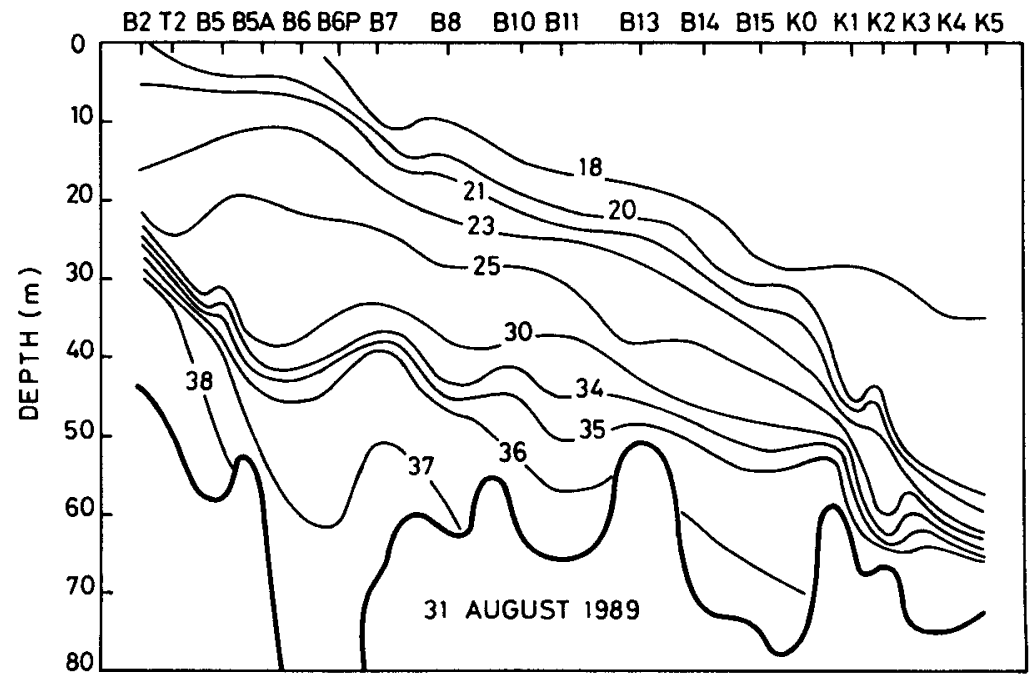

FIG. 3e. Salinity transect in the Bosphorus Strait for August 1989. 
are connected by a subcritical flow. The supercritical condition downstream of the narrowest section would isolate the maximal exchange from the processes taking place farther south in the exit region, similar to the supercritical condition downstream of the northern sill isolating the exchange from the processes occurring in the western Black Sea. The critical flow conditions taking place at the southern extremity of the strait would therefore not influence the maximal exchange.

This form of the flow structure however reveals, as pointed out above, pronounced wind induced variations on time scales of a few days. Accordingly, the anticipated maximal exchange might continuously be in the process of time-dependent adjustment in response to the changing flow conditions. For example, in the case of sufficiently strong upper layer inflow caused by intense northerly winds from the Black Sea (cf. Fig. 3a), the lower layer becomes temporarily blocked at the northern reaches of the strait. The control exerted by the northern sill is then apparently shifted farther south. On the contrary, during the weakening of the northerlies and relaxation of the blockage event, the control moves back to its regular place at the sill crest. The other control which takes place at the constriction, in this case, continues to prevail and isolates the exchange from conditions farther south. In the case of sufficiently weak upper-layer flow conditions, the control at the narrowest section may be lost (cf. Fig. 3e) and the maximal exchange governed by the controls imposed at the northern sill and southern expansion. When strong southerlies persist over the region and the upper layer flow is slowed down, the maximal exchange appears to be maintained by changing the position of the control at the constriction back and forth along the strait. Whenever the southerlies lead to the flow reversals in the surface layer, the whole water column moves in the northern direction in the southern parts of the strait, and the maximal exchange conditions will be lost. This persists until a new two-layer equilibrium state reformed by cessation of the effect of southerlies in the flow structure. The observations associated with such flow reversals have been reported in Latif et al. (1990).

\section{Description of the model}

The mathematical formulation of the model is essentially similar to the two-layer model of Dardanelles Strait described by Oğuz and Sur (1989). The present model, however, incorporates additionally the salt transport equations and associated baroclinic pressure gradient terms in the momentum equations for the layers. The Bosphorus Strait is approximated by a channel of variable depth and width. The channel is assumed to be sufficiently narrow so that a one-dimensional treatment is appropriate. All quantities in each layer therefore depend only on the horizontal coordinate, $x$, taken positive towards the Black Sea. The vertical axis, $z$, is directed upwards from the equilibrium level of the free surface. The initial reference positions of the interface and the impermeable channel floor are respectively situated at $z=-h_{1}(x)$ and $z$ $=-h(x)$. Displacements of the free surface and the interface from their reference levels, as a response to a developing two layer exchange flow, are defined by $\eta_{1}(x, t)$ and $\eta_{2}(x, t)$, respectively. The model incorporates different width specifications for the upper and lower layers; $B_{1}(x, t)$ and $B_{2}(x, t)$, respectively, to account for the width variations in the vertical. Invoking the hydrostatic, incompressibility and Boussinesq approximations, the governing equations can then be written as

$$
\begin{gathered}
\partial\left(H_{1} B_{1}\right) / \partial t+\partial q_{1} / \partial x=B_{i}\left(w_{e 1}-w_{e 2}\right) \\
\partial\left(H_{2} B_{2}\right) / \partial t+\partial q_{2} / \partial x=B_{i}\left(w_{e 2}-w_{e 1}\right) \\
\partial q_{1} / \partial t+\partial\left(u_{1} q_{1}\right) / \partial x \\
=-g B_{1} H_{1}\left[\partial P_{1} / \partial x\right]+B_{1}\left(\tau_{s}-\tau_{i}\right) / \rho_{0} \\
+B_{1}\left(u_{2} w_{e 1}-u_{1} w_{e 2}\right)+\partial\left[N_{1} \partial q_{1} / \partial x\right] / \partial x \\
\partial q_{2} / \partial t+\partial\left(u_{2} q_{2}\right) / \partial x \\
=-g B_{2} H_{2}\left[\partial P_{2} / \partial x\right]+B_{2}\left(\tau_{i}-\tau_{b}\right) / \rho_{0} \\
+B_{2}\left(u_{1} w_{e 2}-u_{2} w_{e 1}\right)+\partial\left[N_{2} \partial q_{2} / \partial x\right] / \partial x \\
\partial\left(H_{1} B_{1} S_{1}\right) / \partial t+\partial\left(q_{1} S_{1}\right) / \partial x=B_{i}\left(S_{2} w_{e 1}-S_{1} w_{e 2}\right) \\
+\partial\left[A_{1} \partial\left(H_{1} B_{1} S_{1}\right) / \partial x\right] / \partial x \\
\partial\left(H_{2} B_{2} S_{2}\right) / \partial t+\partial\left(q_{2} S_{2}\right) / \partial x=B_{i}\left(S_{1} w_{e 2}-S_{2} w_{e 1}\right) \\
+\partial\left[A_{2} \partial\left(H_{2} B_{2} S_{2}\right) / \partial x\right] / \partial x
\end{gathered}
$$

where subscripts 1 and 2 are used to denote variables in the upper and lower layers, respectively. Here $u_{k}$ is the velocity taken positive in the $x$ direction, $q_{k}$ is the volume transport, $S_{k}$ is the salinity, $P_{k}$ is the pressure in each of the layers; $B_{i}(x)$ signifies the width of the channel at the interface whereas $w_{e 1}$ and $w_{e 2}$ represent the entrainment velocities for the convective and turbulent transfers between the layers in the upward and downward directions, respectively. $\partial$ signifies the partial differentiation operator. See also Fig. 4a for the definition of the model parameters.

As in Oguz and Sur (1989), the instantaneous layer thicknesses, $H_{k}$, the volume flow rates, $q_{k}$, and the shear stresses at the free surface, $\tau_{s}$, at the interface, $\tau_{i}$, at the bottom, $\tau_{b}$ are defined respectively by

$$
\begin{aligned}
H_{1} & =h_{1}+\eta_{1}-\eta_{2}, \quad H_{2}=h_{2}+\eta_{2} \\
q_{k} & =B_{k} H_{k} u_{k} \quad(k=1,2) \\
\tau_{s} & =\rho_{s} C_{s}|W| W \\
\tau_{b} & =\rho_{0} C_{b}\left|u_{2}\right| u_{2} \\
\tau_{i} & =\rho_{0} C_{i}\left|u_{1}-u_{2}\right|\left(u_{1}-u_{2}\right) .
\end{aligned}
$$


The two layer formulation presented here is standard and has widespread applications. For example, it is used in the modeling of salinity intrusion in the Danish Sounds by Abbott et al. (1978) on the basis of its two dimensional formulation given by Grubert and Abbott (1972), in the coastal upwelling study described by Thompson (1974), and in the Albeni Inlet circulation by Hodgins (1979).

In Eqs. (2a,b), the integrated pressure gradient terms, which include both barotropic and baroclinic contributions, are expressed by (Hodgins 1979)

$$
\begin{array}{r}
{\left[\partial P_{1} / \partial x\right]=\partial \eta_{1} / \partial x+\frac{1}{2} H_{1} \beta_{S} \partial S_{1} / \partial x} \\
{\left[\partial P_{2} / \partial x\right]=\partial \eta_{1} / \partial x-(1-r) \partial \eta_{2} / \partial x} \\
+H_{1} \beta_{S} \partial S_{1} / \partial x+\frac{1}{2} H_{2} \beta_{S} \partial S_{2} / \partial x
\end{array}
$$

where $r=\rho_{1} / \rho_{2}$ represents the ratio of the upper layer to lower layer density with $\rho_{1}$ and $\rho_{2}$ being related to the salinities by the linear equation of state

$$
\rho_{k}=\rho_{0}\left(1+\beta_{S} S_{k}\right) \quad(k=1,2)
$$

where $\rho_{0}$ is the reference density.

The horizontal diffusion terms introduced in the momentum equations $(2 a, b)$ are effectively used to smooth out any developing discontinuity in the form of a hydraulic jump and therefore to avoid invoking jump conditions in order to continue the solutions beyond the times at which these occur. These terms usually have negligible contribution to the momentum budget of the layers except in the regions of internal hydraulic jumps where they make the numerical solution stable. The horizontal eddy viscosity, $N_{k}$, are parameterized by (Thompson 1974; Stacey and Zedel 1986)

$$
N_{k}=\alpha(\Delta x)^{2}\left|\partial u_{k} / \partial x\right| \quad(k=1,2)
$$

with $\alpha$ representing a disposable parameter chosen arbitrarily, and $\Delta x$ being the horizontal grid increment. The criterion adopted for setting the value of $\alpha$ is to choose its smallest possible value which provides a stable numerical solution. In order to avoid extra empricism in the model, the horizontal diffusion coefficients in Eqs. ( $3 \mathrm{a}, \mathrm{b}), A_{k}$, are assumed to be same with the horizontal eddy viscosities, and therefore we let $A_{k}=N_{k}$ $(k=1,2)$. However, in the final discretization procedure of the salt transport equations, since the onesided scheme employed for the horizontal advection terms include some numerical diffusion, the physical diffusion is dropped from the formulation.

Formulation of the entrainment process for simulating exchanges of mass and momentum between the layers is based on the analysis of turbulent and mean flow energy interactions in the layers. For the case of only one turbulent layer separated by an entraining interface from a nonturbulent layer, entrainment pa- rameterization schemes of differing complexities have been proposed; e.g., for the mixed layer deepening due to the wind-generated turbulence in the upper ocean (Krauss 1977 and references cited therein), or for various classes of motions including dense bottom currents, free penetrative convection, horizontal and vertical buoyant flows (Pedersen 1980). Models dealing with turbulence in both layers and thereby incorporating entrainment in both directions are given by Thompson (1974), Abbott et al. (1978), Christodoulou and Connor (1980), Moller and Pedersen (1983), Kranenburg (1987). Following the work given by Pedersen (1980), a general formulation of the two way entrainment mechanism was recently presented by Sur (1988) and employed in the modeling of water exchange across the Dardanelles Strait (Oğuz and Sur 1989).

The transport equations for the turbulent kinetic energy (TKE) integrated across the layers are written by following Pedersen (1980) and Sur (1988)

$$
\begin{aligned}
& \left(\mathrm{PRD}_{1}-q_{1} \partial e_{1} / \partial x\right)-\mathrm{DIS}_{1}=\frac{1}{2} g^{\prime} H_{1} w_{e 1} \\
& \left(\mathrm{PRD}_{2}-q_{2} \partial e_{2} / \partial x\right)-\mathrm{DIS}_{2}=\frac{1}{2} g^{\prime} H_{2} w_{e 2}
\end{aligned}
$$

where the terms on the left-hand sides represent respectively the total productions of TKE by the vertical shears in the mean flow, gain or loss due to the convective transports by the mean flow and the rates of TKE dissipation. These equations describe utilization of the net energy transferred to turbulence from the mean flow in the entrainment process. Neglecting relatively insignificant increase in the TKE itself of the entrained mass (Pedersen 1980), this entrainment is associated with an increase in the level of potential energy of the entrained water parcels represented by the right hand sides of equations ( $10 \mathrm{a}, \mathrm{b})$. The efficiency of this process is defined as the bulk flux Richardson number, $R_{f}$, by Pedersen (1980)

$$
R_{f}=[(\mathrm{PRD}-q \partial e / \partial x)-\mathrm{DIS}] / \mathrm{PRD} .
$$

The explicit form of the production term in Eq. (11) is obtained by resorting the mean flow kinetic energy equation. This is written for each layer by following Pedersen (1980), Oğuz and Sur (1989)

$$
\begin{aligned}
\mathrm{PRD}_{1}=\left\{\left[\gamma W \tau_{s}+\frac{1}{2}\left(u_{1}-u_{2}\right) \tau_{i}\right] / \rho_{0}\right\} & \\
& +\frac{1}{2}\left(u_{1}-u_{2}\right)^{2} w_{e 1} \\
\mathrm{PRD}_{2}=\left\{\left[\frac{1}{2}\left(u_{1}-u_{2}\right) \tau_{i}+\right.\right. & \left.\left.\beta u_{2} \tau_{b}\right] / \rho_{0}\right\} \\
& +\frac{1}{2}\left(u_{1}-u_{2}\right)^{2} w_{e 2}
\end{aligned}
$$

where the first and second terms express the TKE production associated with the work done by the boundary 
stresses and the third terms are related to the loss of mean flow kinetic energies due to the velocity shear at the interface.

Utilizing the TKE equations given by (10a,b) and the form of vertical production terms expressed by $(12 a, b)$, the entrainment velocities in the upward and downward directions across the interface may be obtained from the definition of $R_{f}$ in (11) as

$$
\begin{aligned}
& w_{e 1}=2 R_{f} \frac{\left[\gamma W \tau_{s}+\frac{1}{2}\left(u_{1}-u_{2}\right) \tau_{i}\right] / \rho_{0}}{\left[g^{\prime} H_{1}-R_{f}\left(u_{1}-u_{2}\right)^{2}\right]} \\
& w_{e 2}=2 R_{f} \frac{\left[\beta u_{2} \tau_{b}+\frac{1}{2}\left(u_{1}-u_{2}\right) \tau_{i}\right] / \rho_{0}}{\left[g^{\prime} H_{2}-R_{f}\left(u_{2}-u_{1}\right)^{2}\right]} .
\end{aligned}
$$

The forms of $(13 \mathrm{a}, \mathrm{b})$ are also similar to those presented by Kranenburg (1987). The latter work, however, applies different weighting factors for each production term. Therefore, as opposed to a common coefficient, $R_{f}$, used for the contribution of each production term in this formulation, different coefficients are proposed. Their values are obtained by laboratory measurements, but agree with the range of values of $R_{f}$ proposed by Pedersen (1980). Utilizing an extensive set of laboratory and field data, Pedersen (1980) states the order of magnitude of the bulk flux Richardson number as $0.04<\mathrm{O}\left(R_{f}\right)<0.18$. This range of values is also in accord with those given by Kullenberg (1977) and Bush (1981).

\section{a. Boundary conditions}

The strait is extended partially on both sides into the adjacent basins to locate the open boundaries further away from the actual exit sections so that the contribution of northern sill region and the abruptly widening Marmara exit region in the formation of anticipated internal hydraulic adjustments of the flow can be simulated properly. Subcritical flow conditions are specified at both ends of the idealized channel by making use of the radiation conditions similar to those prescribed in Oguz and Sur (1989). At the Black Sea end of the model channel $(x=L)$, the radiation conditions take the forms

$$
\begin{aligned}
\eta_{1}=(g h)^{-1 / 2}\left[h_{1} u_{1}+h_{2} u_{2}+2 Q_{1 L} / B\right] \\
\eta_{2}=\left(h_{2} / h\right) \eta_{1}-\left(h_{1} h_{2} / g^{\prime} h\right)^{1 / 2} \\
\times\left[u_{1}-u_{2}+Q_{2 L} h /\left(B h_{1} h_{2}\right)\right] .
\end{aligned}
$$

Similarly, at the Marmara end of the channel $(x=0)$, the conditions are

$$
\begin{aligned}
& \eta_{1}=-(g h)^{-1 / 2}\left[h_{1} u_{1}+h_{2} u_{2}+2 Q_{10} / B\right] \\
& \eta_{2}=\left(h_{2} / h\right) \eta_{1}+\left(h_{1} h_{2} / g^{\prime} h\right)^{1 / 2} \\
& \times {\left[u_{1}-u_{2}+Q_{20} h /\left(B h_{1} h_{2}\right)\right] }
\end{aligned}
$$

where $Q_{L}$ and $Q_{0}$ are the prescribed volume transports used to force the two-layer flow system at the Black Sea and Marmara Sea boundaries, respectively; $h_{1}$ and $h_{2}$ define the equilibrium depths of the upper and lower layers, respectively, with $h=h_{1}+h_{2}$ signifying the total undisturbed depth (see Fig. 4a). Application of similar conditions with somewhat different formulations have been given by Pearson and Winter (1984) and Kantha (1985).

Equations ( $3 a, b)$ are complemented by the boundary conditions which involve prescription of a salinity value of the inflowing water in a layer whereas the salinity of outflowing water is determined by the model by the use of Eqs. (3a,b). Therefore, we apply

$$
S_{1}=S_{1 L} \quad \text { at } \quad x=L, \quad S_{2}=S_{20} \quad \text { at } \quad x=0
$$

where $S_{1 L}$ and $S_{20}$ signify the prescribed salinities at the upper layer of the Black Sea end and at the lower layer of the Marmara exit, respectively.

\section{b. Numerical procedure}

The set of equations governing the model is discretized by the forward-in-time and centered-in-space explicit finite-differencing method. The horizontal advection terms in Eqs. (3a,b) are treated by the onesided scheme referencing only to the upstream values of the salinities and transports. The implied numerical diffusion introduced by the one-sided scheme does however not dominate the results owing to the use of small time step ( $\Delta t=10 \mathrm{~s})$ and the grid point $(\Delta x$ $=500 \mathrm{~m}$ ). The numerical discretization is made on the staggered grid so that the thicknesses and transports in the layers are determined at consecutive grid points. The salinities are updated at the same points where the layer thicknesses are currently evaluated.

In the numerical discretization procedure, the boundary conditions (14a-d) are actually applied at the points $x=\Delta x$ and $x=L-\Delta x$ which correspond to the current points of the staggered grid system. The values of $\eta_{1}$ and $\eta_{2}$ at these current points are specified by averaging from the adjacent grid points which therefore introduces $\eta_{1}$ and $\eta_{2}$ at the boundaries; $u_{1}$ and $u_{2}$ are specified explicitly in terms of their known values obtained at the previous time step. It is therefore evident from Eqs. (14a-d) that the final specifications of $\eta_{1}$ and $\eta_{2}$ at the boundaries involve a combination of the externally specified forcing in terms of the volume transports $Q_{L}$ and $Q_{0}$ as well as the interior response of the model (defined by the first terms on the right hand sides of Eqs. 14a-d) at the points adjacent to the open boundaries.

The model region is divided into a total of 85 sections separated from each other by a distance of $500 \mathrm{~m}$. The idealized width and depth structures, representative of the characteristic features of the Bosphorus morphology, are specified at each of these sections from navigational charts. The representative bottom topography 


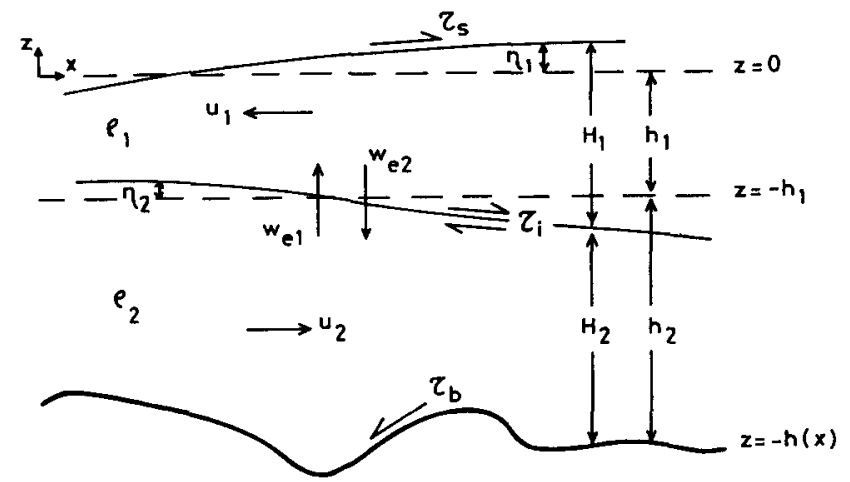

FIG. 4a. Definition sketch for some model parameters.

incorporated into the model is given in Fig. 5b. The average widths for the layers are calculated from the actual bathymetric data specified at $10 \mathrm{~m}$ intervals in the vertical and subsequently interpolated to $1 \mathrm{~m}$ intervals at each grid point. Subsequently, $B_{1}(x, t)$ and $B_{2}(x, t)$ are obtained by averaging through the layer depths specified according to the position of the interface at each grid point and at each time step. A representative width variations for a particular steady state position of interface is shown in Fig. $4 \mathrm{~b}$. The values of various parameters used in the model are shown in Table 1. Initially constant salinities of $18 \mathrm{ppt}$ in the upper and $38 \mathrm{ppt}$ in the lower layer are specified along the channel. These values correspond to their boundary values $S_{1 L}, S_{20}$ specified at Eq. (15).

The discretized form of the equations are integrated ahead in time from an initial state of rest until all transients are dissipated at all grid points by the friction in the system and are radiated away through the open boundaries by the boundary conditions. The stability of the numerical scheme is secured by taking $\Delta t=10$ sec. It should be noted that the radiation conditions specified at the open boundaries are found very efficient in eliminating the transient response and establishment of the eventual steady state response in a relatively short period of the time integration. The eventual steady state fields are established after typically 60-70 hours of time integration. In the steady state, all quantities (e.g., the layer thicknesses, volume and salt transports) show negligible differences between consecutive time steps. The model results are found to be independent from the initial conditions. The ultimate steady fields are developed within the strait as a response to the forcings through the boundary conditions. In particular, the initial position of the interface which has been taken to be a linearly sloping interface within the channel is adjusted gradually to its final position in response to the prescribed boundary forcings. Furthermore, the numerical discretization procedure does not introduce any source/sink of salt, and the total salt flux through the channel becomes approximately zero (with a difference of about $5 \%$ between the values at the two ends) at the end of the time integration of about $60-70$ hours.

\section{Results of the model experiments}

General features of the quasi-steady two-way exchange flow structure, resulting from steady forcings prescribed at the Black Sea boundary of the upper layer and at the Marmara Sea boundary of the lower layer, are described in this section. The primary purpose of the numerical experiments is to be able to identify the general internal hydraulic features and their dependence on the changing volume transports in the layers. The volume transports specified in the numerical experiments corresponds to their moderate range of values and therefore exclude cases with extremely high upper and lower layer flows leading to the blockage of either layer. The time dependent adjustment mechanisms associated with short-term increases in the prevailing wind conditions have also not been studied. These will be covered separately in future studies.

The values of external parameters specified in the model experiments are obtained on the basis of various

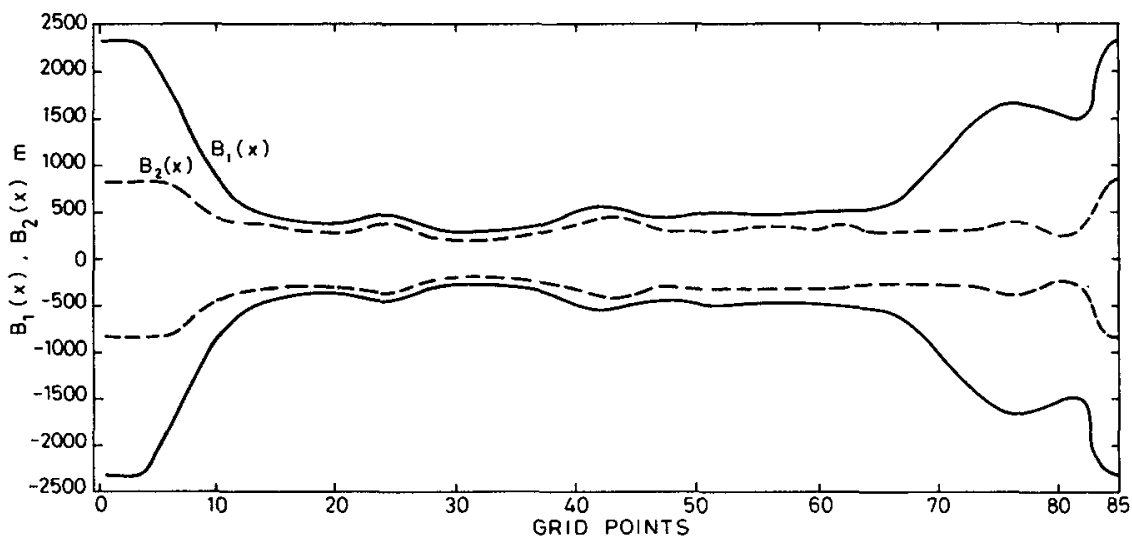

FIG. 4b. One-dimensional idealized channel representation of the Bosphorus geometry for the upper and lower layers. 


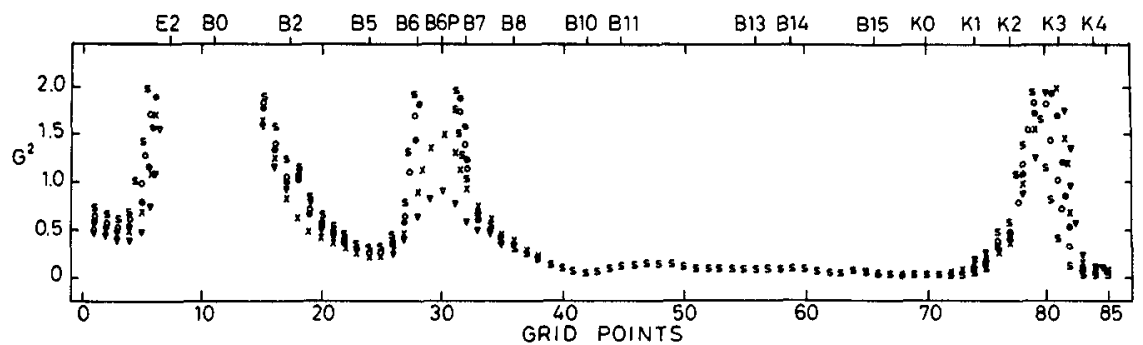

FIG. 5a. Computed variations of the composite Froude number for various values of $q_{0}: 4380$ $\mathrm{m}^{3} \mathrm{~s}^{-1}(\nabla), 10500 \mathrm{~m}^{3} \mathrm{~s}^{-1}(\times), 12350 \mathrm{~m}^{3} \mathrm{~s}^{-1}(\bullet), 16600 \mathrm{~m}^{3} \mathrm{~s}^{-1}(O)$ and $21765 \mathrm{~m}^{3} \mathrm{~s}^{-1}(\mathrm{~s})$.

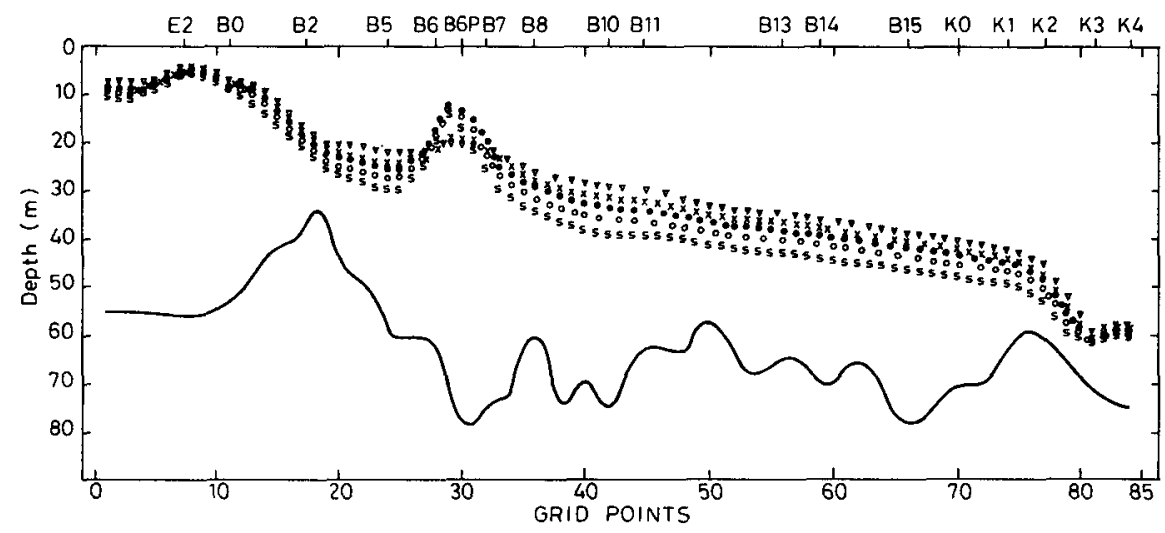

FIG. 5b. Computed variations of the interface depth for various values of $q_{0}: 4380 \mathrm{~m}^{3} \mathrm{~s}^{-1}(\nabla)$, $10500 \mathrm{~m}^{3} \mathrm{~s}^{-1}(\times), 12350 \mathrm{~m}^{3} \mathrm{~s}^{-1}(\bullet), 16600 \mathrm{~m}^{3} \mathrm{~s}^{-1}(O)$ and $21765 \mathrm{~m}^{3} \mathrm{~s}^{-1}(\mathrm{~s})$.

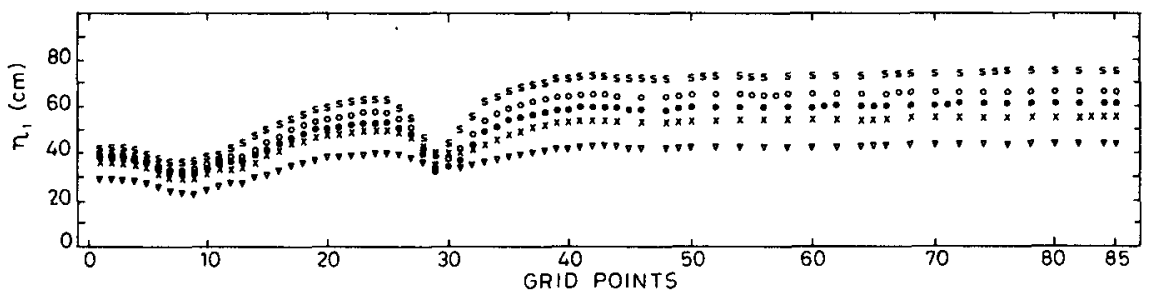

FIG. 5c. Computed variations of the free surface elevation for various values of $q_{0}: 4380 \mathrm{~m}^{3}$ $\mathrm{s}^{-1}(\nabla), 10500 \mathrm{~m}^{3} \mathrm{~s}^{-1}(\times), 12350 \mathrm{~m}^{3} \mathrm{~s}^{-1}(\bullet), 16600 \mathrm{~m}^{3} \mathrm{~s}^{-1}(O)$ and $21765 \mathrm{~m}^{3} \mathrm{~s}^{-1}(\mathrm{~s})$.
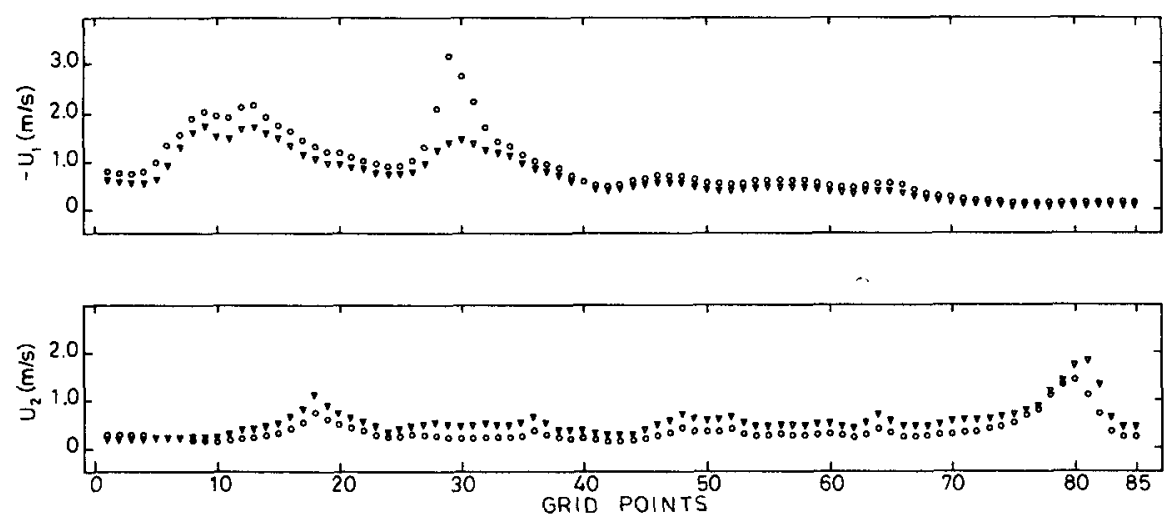

FIG. 5d. Computed variations of the upper and lower layer currents for values of $q_{0}: 4380 \mathrm{~m}^{3} \mathrm{~s}^{-1}(\nabla)$ and $16600 \mathrm{~m}^{3} \mathrm{~s}^{-1}(O)$. 
TABLE 1. Values of parameters used in the numerical model.

$\begin{aligned} \alpha & =5 \\ \beta & =1 / 3 \\ R_{f} & =0.13 \\ W & =0 \\ \beta_{S} & =0.00075 \\ g & =0.81 \mathrm{~m} \mathrm{~s}^{-2} \\ \rho_{0} & =1000 \mathrm{~kg} \mathrm{~m}^{-3} \\ \Delta t & =10 \mathrm{~s} \\ \Delta x & =500 \mathrm{~m} \\ S_{1 L} & =18 \mathrm{ppt} \\ S_{20} & =38 \mathrm{ppt} \\ C_{i} & =0.0001 \\ C_{b} & =0.0023 \\ \gamma & =0.02\end{aligned}$

sensitivity studies. It turns out that the typical values of $\alpha$ should be chosen smaller than 10 for the solutions unaffected appreciably by the excessive horizontal friction. The values with $\alpha \gg 10$, introducing relatively stronger horizontal friction into the system, lead to considerable smoothing of the interface and currents in the regions of controlled flow conditions. In the numerical experiments, we set $\alpha=5$. The bottom friction coefficient appears not to be a sensitive parameter for the two-layer exchange flow system in the Bosphorus Strait. For its range of values frequently cited in the literature, between 0.0010 and 0.0030 , the internal hydraulic characteristics of the flow remain unchanged except for some minor modifications in the lower layer currents. The value of interfacial friction coefficient chosen in the experiments, however, appears to be crucially important. The experimentation shows that the value of $C_{i}$ should be on the order of $\mathrm{O}\left(10^{-4}\right)$ for the Bosphorus. This is somewhat smaller than the values generally employed in numerical model studies, but supported by the experimental findings of Pedersen (1980) for various classes of supercritical flows in some estuaries and fjords. The basic parametric setting for the experiments described here is shown in Table 1. The details of the model dependence on the external parameters are essentially same with those given in the Og̈uz and Sur (1989), and therefore will not be repeated.

For various values of the net barotropic flow, $q_{0}$, through the strait, the steady-state along-channel variations of the composite Froude number, the interface height and the free surface elevation as well as currents in the layers are presented in Figs. 5a-d, respectively. The composite Froude number, $G^{2}$, is defined here as $G^{2}=F_{1}^{2}+F_{2}^{2}$ with $F_{k}^{2}=u_{k}^{2} / g^{\prime} H_{k}(k=1,2)$ signifying the densimetric Froude number for each layer.

Figure 5a reveals the presence of three distinct regions of supercritical $\left(G^{2}>1\right)$ flow along the strait. The lower layer water of Mediterranean origin flows subcritically $\left(F_{2}{ }^{2}<1\right)$ towards the northern exit region. In the pre-Bosphorus channel, weak upper layer currents within a sufficiently deep layer of about $50 \mathrm{~m}$ result in very small values of $F_{1}{ }^{2}$. But, as the underflow surmounts the sill, $F_{2}{ }^{2}$ approaches unity and the critical condition $\left(G^{2}=1\right)$ occurs at grid point 78 corresponding to $1 \mathrm{~km}$ downstream of the sill crest. The supercritical regime of the underflow encompasses a distance $1 \mathrm{~km}$ downstream of the control section with the highest values of $G^{2}$ taking place at grid point 80 . Thereafter, $G^{2}$ profiles decrease sharply to their subcritical values so that the Mediterranean effluent eventually joins the Black Sea subcritically. We note that sharp reductions in $G^{2}$ profiles from the maximal supercritical values to those of subcritical simulate the discontinuous process of internal hydraulic jump.

The displacement of the control section from the sill crest to a position farther downstream may in fact be associated with frictional effects. Using a reduced gravity model for an underflow beneath an infinitely deep and motionless upper layer, Pratt (1986) demonstrates that the bottom friction moves a control section from the sill crest to a downstream position whose location depends on the value of the friction coefficient as well as the width and depth variations in the region.

In the southerly direction, upper layer water of the Black Sea origin flows subcritically (with $F_{1}{ }^{2} \approx 0.1$ ) in the northern half of the strait. Upon reaching the constricted region, the densimetric Froude number of the upper layer starts increasing and becomes unity between grid points 33 and 32 , corresponding to the narrowest section of the channel. The upper layer flow then proceeds supercritically up to grid point 29 and returns abruptly to the subcritical regime immediately south of grid point 28. Towards the Marmara extremity of the strait, the subcritical values of $G^{2}$ increase gradually from its typical values of 0.3 attaining just downstream of the hydraulic jump. A third internal hydraulic adjustment occurs as the densimetric Froude number of the upper layer becomes unity between grid points 16 and 18 depending on the particular value of $q_{0}$. This region is approximately $3 \mathrm{~km}$ away from the Marmara exit and corresponds to the Üsküdar-Beşiktaş section of the strait (cf. Fig. 1b and Fig. 2). The region is known to present a recirculation zone in the surface layer along the Beşiktaş coast (see dotted area in Fig. 2 ) and the southerly flowing mainstream is therefore confined into the narrow channel at the opposite Üsküdar side (Özsoy et al. 1986). This recirculation zone is taken into account in the model by excluding this area as we approximate the upper-layer width structure (cf. Fig. 4b). Consequently, the shallower interface depth together with the strong currents, typically in excess of $2.0 \mathrm{~m} \mathrm{~s}^{-1}$, flowing primarily through a narrow and shallow layer in the region give rise to a critical control of the upper layer flow. The region of supercritical flow regime extends up to the Marmara exit region (grid point 6) and occupies a distance of about $5 \mathrm{~km}$. Transition to the subcritical regime of the Marmara Sea occurs south of grid point 6 through a sharp reduction in the values of $G^{2}$ below unity. On 
the other hand, when the width of the upper layer is taken without excluding the recirculation zone, this region then no longer exhibits the internal hydraulic control for the upper layer flow. The control, in this case, is still present but shifted farther south to the abruptly widening exit section.

The model computations show that the northern sill and the southern exit regions always possess the critical controls regardless of the value of $q_{0}$. The presence of internal hydraulic adjustment of the flow at the constricted region is however found to depend on the magnitude of the net barotropic flow. For example, for the case $q_{0}=4380 \mathrm{~m}^{3} \mathrm{~s}^{-1}$ shown in Fig. 5a, the composite Froude number at the constricted region does not exceed unity. In this case, the maximal exchange is therefore formed due to the controls exercised at the northern sill and the southern exit regions.

This feature of the numerical experiments supports the observational evidence that the hydraulic control at the narrowest section may disappear during sufficiently weak upper-layer flow conditions, corresponding generally to the calm periods of the late spring and winter months when the Black Sea inflow into the strait decreases substantially (Özsoy et al. 1986). Dependence of this control on the values of the friction coefficients is further shown in Fig. 6.

Figure $5 \mathrm{~b}$ represents corresponding variations of the interface height for various values of $q_{0}$. The interface possesses almost linear variations along most part of the strait except strongly nonlinear, asymmetrical variations in the regions where $G^{2}$ profiles yield critical transitions. The interfaces are typically located about 10-15 $\mathrm{m}$ above the sill crest in the pre-Bosphorus channel and tilt linearly upwards in the southern direction towards the constricted region with a typical slope $20 \mathrm{~m} / 20 \mathrm{~km} \approx \mathrm{O}\left(10^{-3}\right)$. To the north of the sill, as the lower layer flow undergoes critical transition, the interface depths decline sharply towards the bottom up to grid section 80 at which $G^{2}$ attain their highest supercritical values. Subsequently, the interface depths rise in the region of the internal hydraulic jump. The interface height profiles then show smooth variations in the subcritical region at the Black Sea extremity of the channel.

As the upper layer flow passes through the constricted region and the composite Froude number exceeds critical value, the interface profiles display considerable upward tilting towards the free surface. Their shallowest positions $(\sim 15 \mathrm{~m})$ occur at grid point 29 corresponding to the region of maximal supercritical values of $G^{2}$. Farther south, in the adjustment region of the upper layer flow to the subsequent subcritical conditions, the interface heights deepen by about 10 $\mathrm{m}$. As the upper layer flow reaches the southern exit region where $G^{2}$ profiles have their most pronounced variations, the interface depths start rising towards the free surface and the upper layer becomes shallower towards the exit section. Transition of the upper layer flow to the subcritical regime occurs farther south near grid point 6 by the deepening of the interface by about $5 \mathrm{~m}$. These features of the interface depth appear to be in close agreement with the form of isohalines shown in Fig. 3a-e.

The corresponding distributions of the free surface along the strait, displayed in Fig. 5c, also show linear variations between the northern sill and the constricted region. This is followed by a region of considerable reduction in the free surface position with minimum values occurring at the point of the shallowest interface depth. Farther southward, the free surface is elevated upwards in the transition region to the subcritical flow regime and then becomes shallower towards the Marmara exit of the strait. The difference in the free surface elevation between the northern sill and the constricted region varies considerably with the magnitude of net barotropic flow and could be as much as about $40 \mathrm{~cm}$.

The structures of upper and lower layer currents are consistent with the internal hydraulic features described

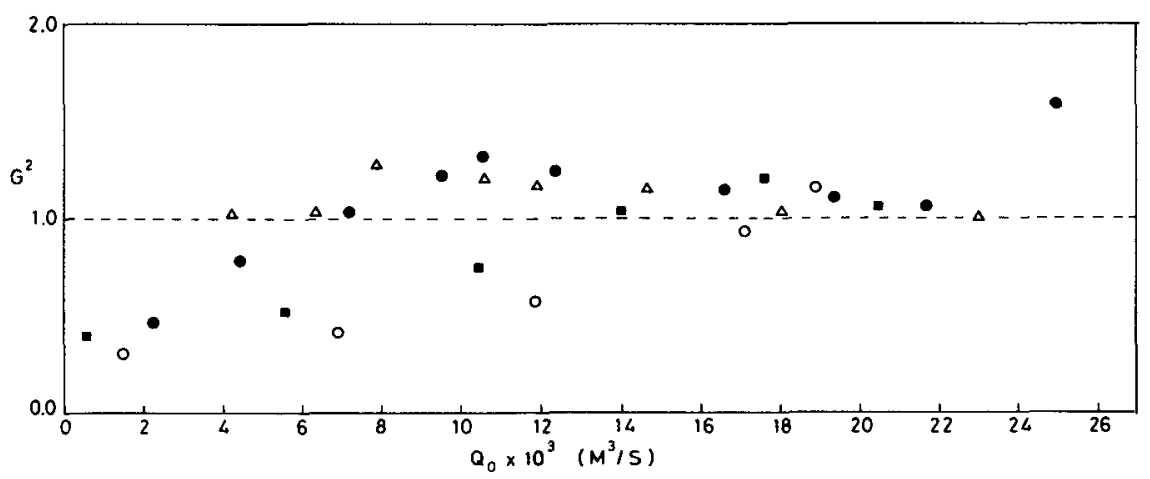

FIG. 6. Composite Froude number versus the net barotropic flow at grid point 32 for different values of friction coefficients with $C_{b}=0.0023$ and (a): $C_{i}=0.0005(\mathrm{O}),(\mathrm{b}): C_{i}=0.0003(\mathrm{a})$, (c): $C_{i}=0.0001(\bullet)$ and with (d): $C_{b}=0.0010, C_{i}=0.0001(\nabla)$. 
above. Figure 5d displays variations for two somewhat extreme values of $q_{0}$ corresponding to 4380 and 16600 $\mathrm{m}^{3} \mathrm{~s}^{-1}$. In the northern part of the strait where $F_{1}^{2} \ll 1$ and the interface attains almost linear variations (except the sill region in the pre-Bosphorus channel), the upper layer currents generally do not differ from each other and do not exceed $0.5 \mathrm{~m} \mathrm{~s}^{-1}$. However, as the upper layer water of Black Sea origin passes through the control sections at the constricted region and the southern exit region, the upper layer currents accelerate and become much stronger, typically exceeding the values of about $2.0 \mathrm{~m} \mathrm{~s}^{-1}$. Even in the absence of the hydraulic control for the case of $q_{0}=4380 \mathrm{~m}^{3} \mathrm{~s}^{-1}$, the upper layer currents may be as high as $1.5 \mathrm{~m} \mathrm{~s}^{-1}$. They decrease, however, to about $1.0 \mathrm{~m} \mathrm{~s}^{-1}$ in the subcritical regimes to the south of the critical controls.

The currents in the lower layer are generally smaller than $0.5 \mathrm{~m} \mathrm{~s}^{-1}$ and do not reflect much changes up to the northern exit region with an exception of slight increase over the southern sill region. Significant changes are noted, however, in the northern sill region where the internal hydraulic control gives rise to acceleration of the flow and thereby increase of the currents to the values about $1.5 \mathrm{~m} \mathrm{~s}^{-1}$. The lower layer currents decrease sharply to values less than $0.5 \mathrm{~m} \mathrm{~s}^{-1}$ as the flow decelerates and joins subcritically to the Black Sea shelf region.

Figure 6 describes how the presence of an internal hydraulic control in the constricted region depends on the magnitude of net barotropic flow for different values of the friction coefficients. It essentially shows how the limiting value of $q_{0}$ required for the existence of the contraction control changes with the values of internal and bottom friction coefficients specified in the model. In the figure, the points with $G^{2}>1$ represent the supercritical upper-layer flow regime at a section immediately adjacent to the critical control, which generally corresponds to grid section 32 . The points with $G^{2}<1$, on the other hand, mark the highest possible subcritical value of the composite Froude number in the constricted region when the particular values of $q_{0}$ chosen in the experiments are less than its limiting value to give rise the hydraulic control.

Four different cases, designated by (a)-(d), are presented in Fig. 6 corresponding to four different set of friction coefficients. In the cases of (a)-(c), the bottom friction coefficient is taken as $C_{b}=0.0023$ whereas the internal friction coefficient, $C_{i}$, accepts three different values; $0.0005,0.0003$ and 0.0001 , respectively. The limiting values of net barotropic flow, $q_{0}{ }^{c}$, are found to be approximately equal to $17000 \mathrm{~m}^{3} \mathrm{~s}^{-1}, 14000$ $\mathrm{m}^{3} \mathrm{~s}^{-1}$ and $7000 \mathrm{~m}^{3} \mathrm{~s}^{-1}$, respectively, for these three cases and therefore imply that $q_{0}{ }^{c}$ increases with the increasing values of $C_{i}$. The bottom friction coefficient also has similar effect on the existence of the contraction control. Comparing cases (c) and (d) in which $C_{i}$ $=0.0010$ but $C_{b}$ is assigned different values of 0.0023 and 0.0010 , respectively, indicates that the latter requires smaller value of $q_{0}^{c}\left(\approx 4000 \mathrm{~m}^{3} \mathrm{~s}^{-1}\right)$ for the presence of an internal hydraulic adjustment in the constricted region.

These results may also give an indication for the most appropriate choice of the value of internal frictional coefficient in the model. We recall that the critical control at the contraction occurs most of the time during the year for a wide range of net barotropic flow conditions except for its sufficiently small values. Therefore, the choice of internal friction coefficient with $C_{i} \geqslant 0.0003$ would probably be unrealistic since the corresponding values of $q_{0}^{c}\left(\geqslant 14000 \mathrm{~m}^{3} \mathrm{~s}^{-1}\right)$ would require unrealistically high values of the surface flow to give rise to controlled flow condition at the constricted region.

The internal hydraulic characteristics of the flow have notable contributions to the vertical exchange taking place between the layers due to the entrainment process. Figures $7 \mathrm{a}, \mathrm{b}$ displaying the along-channel variations of the transports and salinities in the layers for various values of $q_{0}$, reveal that the largest changes occur in the supercritical regions associated with the critical controls. The upper layer flow is partially transferred into the lower layer in the supercritical region downstream of the northern sill control. The underflow exiting from the strait therefore increases partially and carries some amount of Black Sea water back to its origin. The lower layer salinity, prescribed as $38 \mathrm{ppt}$ at the Marmara end, reduces substantially, by about 4$5 \mathrm{ppt}$, in the region. The most drastic changes are observed, however, as the strait expands abruptly into the Bosphorus-Marmara Sea junction region. Almost half of the lower layer flow entering into the strait from the eastern Marmara basin is entrained by the upper layer in this junction region. The upper-layer average salinity, which has a prescribed value of $18 \mathrm{ppt}$ at the Black Sea end, increases accordingly and may reach 23-25 ppt. In the constricted region, changes in the transports and salinities, however, depend on the presence of a critical control as well as the magnitude of the net barotropic flow discussed earlier. They are, however, much weaker as compared to those occurring near the controls established at the two extremities of the strait. The form of layer salinities computed by the model is consistent with those obtained by observations for which an example is depicted in Fig. 8.

Finally, on the basis of various sets of experiments with different values of frictional coefficients and the net barotropic flow in the strait, we present in Fig. 9 the dependence of the transports $\left(q_{1}, q_{2}\right)$ and the free surface elevation difference, $\Delta \eta_{1}$, on $q_{0}$. The transports which attain almost constant values in the region between the northern sill and the contraction are accepted as the representative values of $q_{1}$ and $q_{2}$ whereas the maximum elevation differences between the two exit controls are specified for the values of $\Delta \eta_{1}$. It is shown 

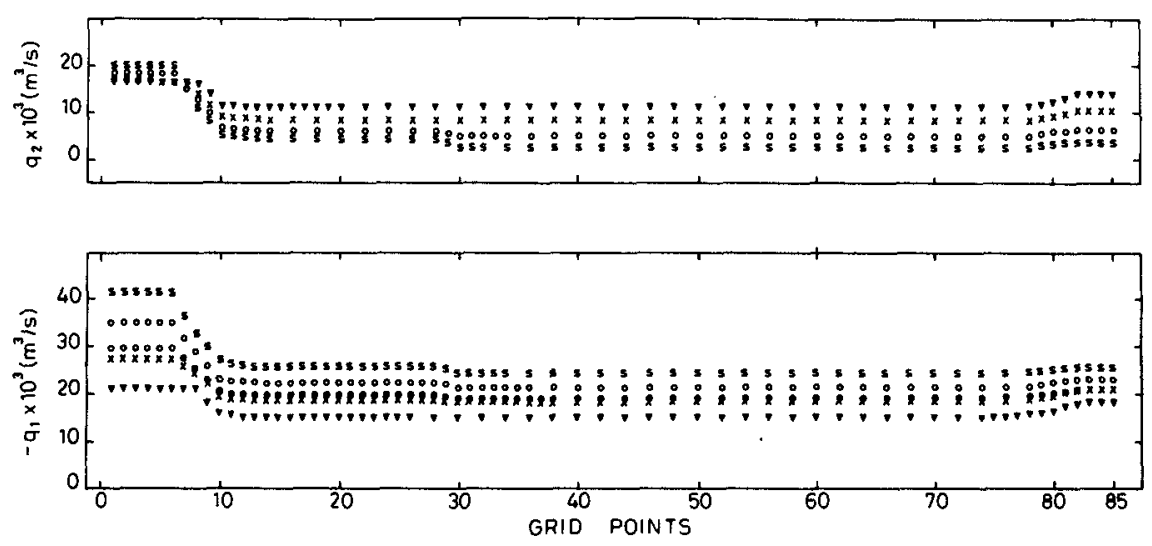

FIG. 7a. Computed variations of the upper and lower layer transports for values of $q_{0}$ : $4380 \mathrm{~m}^{3} \mathrm{~s}^{-1}(\nabla), 10500 \mathrm{~m}^{3} \mathrm{~s}^{-1}(X), 16600 \mathrm{~m}^{3} \mathrm{~s}^{-1}(O)$ and $21765 \mathrm{~m}^{3} \mathrm{~s}^{-1}(\mathrm{~s})$.

that they all change linearly with $q_{0}$ for its range of interest in the Bosphorus Strait. The lower layer transport vanishes approximately for $q_{0} \geqslant 26000 \mathrm{~m}^{3} \mathrm{~s}^{-1}$ in which case the northern reaches of the channel are occupied entirely by the Black Sea water. The transports do not sensitively depend on the friction present in the system for the higher values of $q_{0}$. For smaller values of $q_{0}$, on the other hand, the frictional effects become more important for the transports. Increased friction leads to relatively weaker transports in the layers. An opposite relationship, however, exists between $\Delta \eta_{1}$ and $q_{0}$. As the net barotropic flow weakens, the elevation difference becomes independent of the frictional effects, and attains a value of about $18-20 \mathrm{~cm}$. For larger values of $q_{0}$, elevation difference varies between 39 and $46 \mathrm{~cm}$ with smaller values of the frictional coefficients giving rise to higher elevation differences.

It may be interesting further to compare the layer transports shown in Fig. 9 with those obtained by the analytical model of Farmer and Armi (1986, hereafter referred to as FA). The latter model investigates a two- layer hydraulically controlled maximal exchange through a channel by considering the steady, homogeneous, frictionless, immiscible flow conditions and assuming the rigid-lid approximation for the free surface. The channel possesses a combination of a sill and contraction with the sill being situated adjacent to the deep reservoir of low salinity water. The reservoir containing the dense water lies outside the channel terminated through a contraction at the exit. The dense water, constituting the lower layer in the channel, flows over the sill and then joins the low density basin in a supercritical state below the deep layer of low salinity waters. Similarly, the surface flow issuing from the channel joins the high density reservoir supercritically. In this way, the flow is controlled both at the sill crest and the contraction, and the movement of the fluid between two basins is fully determined by conditions within the channel.

The FA analysis of maximal exchange due to the controls at the constricted region and the northern sill of the Bosphorus Strait requires the simultaneous so-
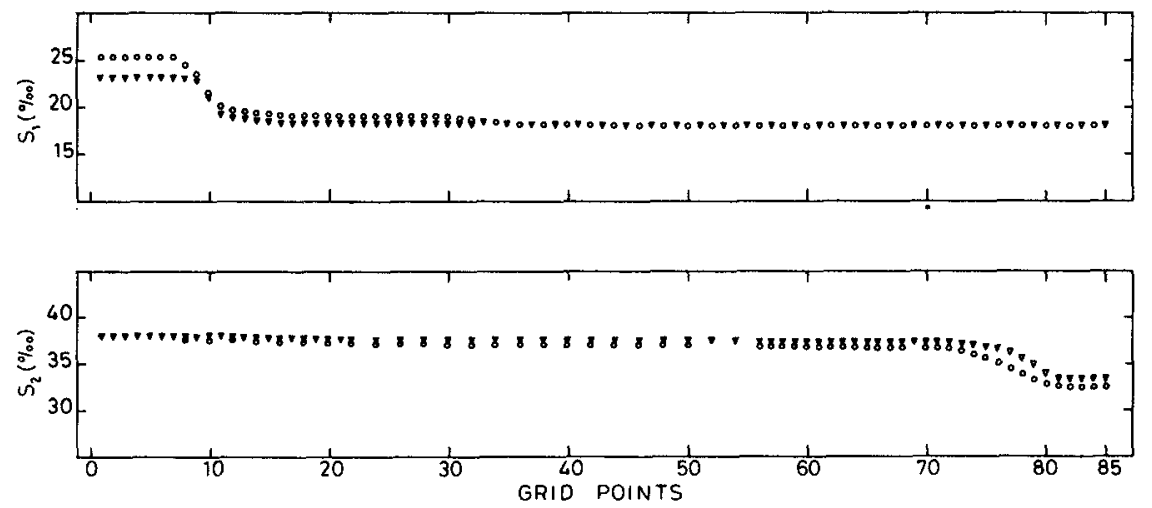

FIG. 7b. Computed variations of the upper and lower layer salinities for values of $q_{0}: 4380 \mathrm{~m}^{3} \mathrm{~s}^{-1}(\nabla)$ and $16600 \mathrm{~m}^{3} \mathrm{~s}^{-1}(O)$. 


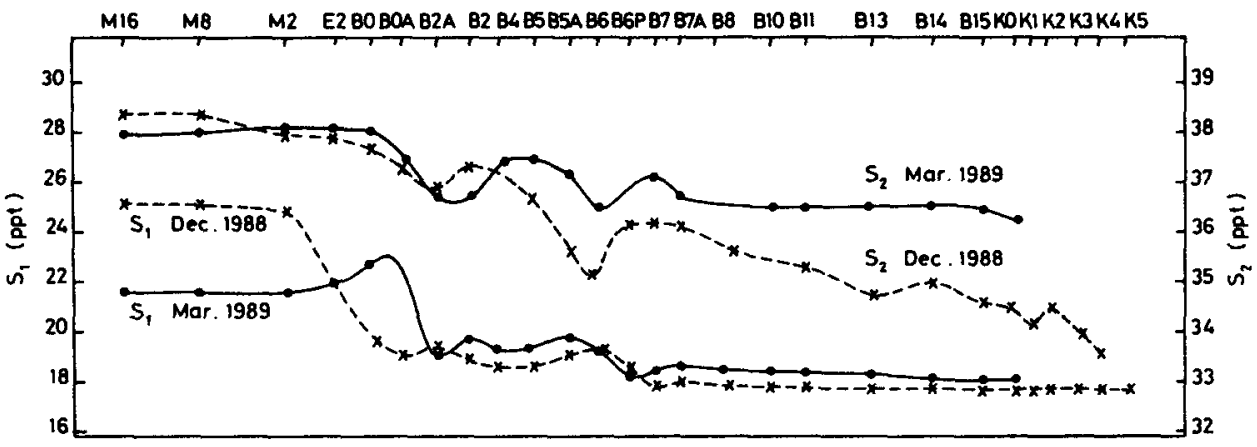

FIG. 8. Average salinities in the upper layer $\left(S_{1}\right)$ and in the lower layer $\left(S_{2}\right)$ in the Bosphorus Strait for December $1988(X)$ and March $1989(\bullet)$.

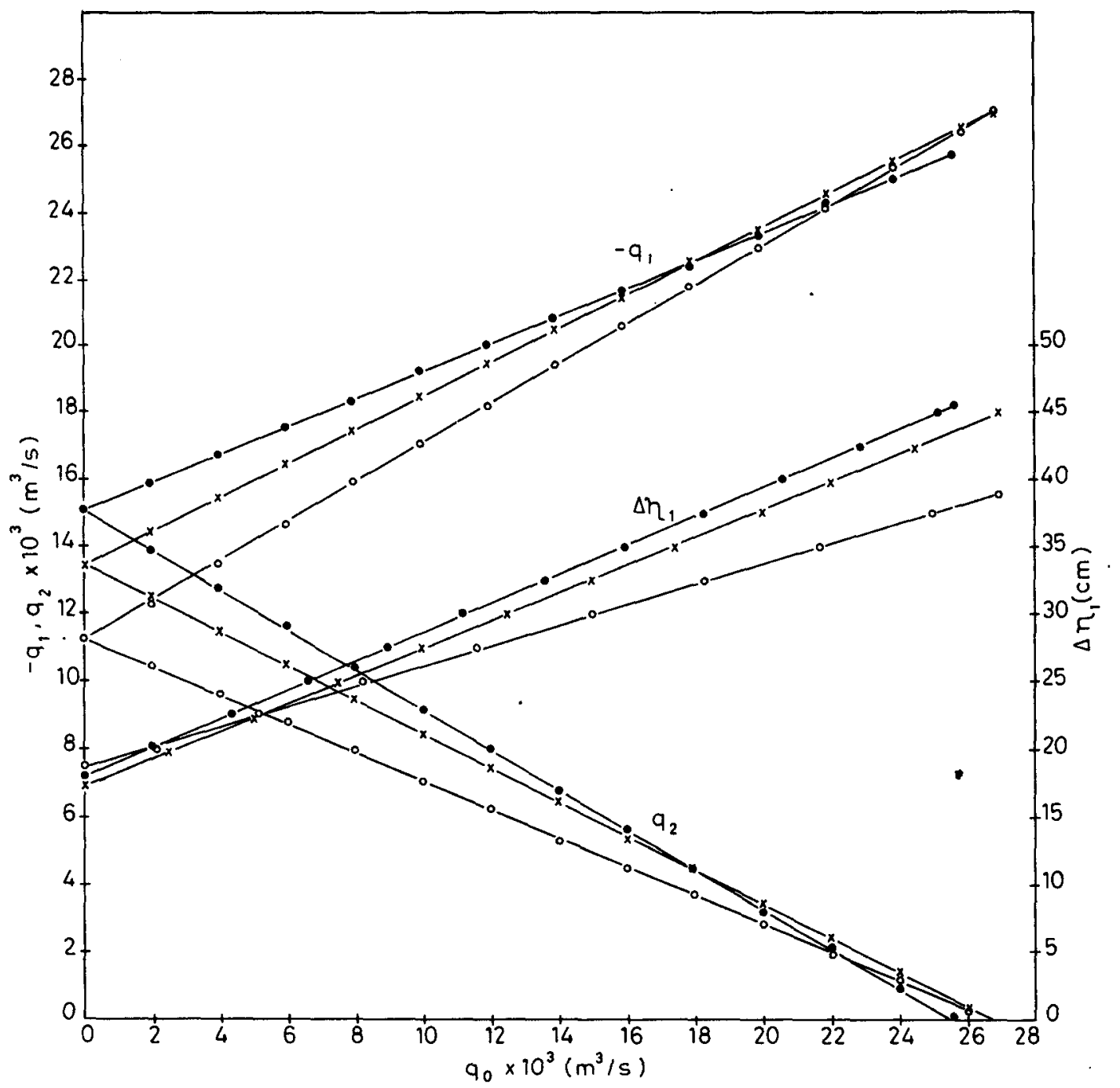

FIG. 9. Upper and lower layer transports and free surface elevation difference versus $q_{0}$ for different set of friction coefficients with $C_{b}=0.0010$ and $C_{i}=0.0001(\bullet), C_{b}=0.0023$ and $C_{i}=0.0003(\times)$ and $C_{b}=0.0023$ and $C_{i}=0.0003$ (O). 
TABLE 2. Values of parameters used in the FA model.

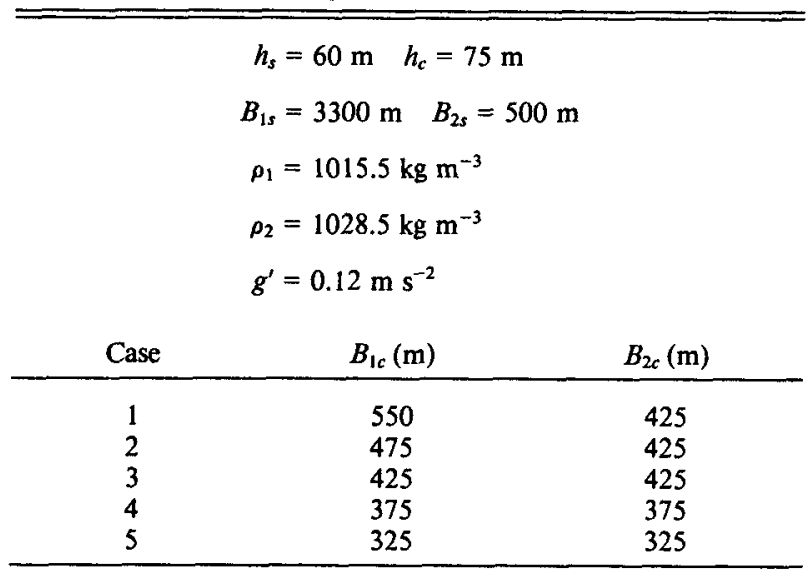

lutions of the following set of equations (Farmer and Armi 1986):

$$
\begin{aligned}
\frac{u_{1 a}^{2}}{g^{\prime} H_{1 a}}+\frac{u_{2 a}^{2}}{g^{\prime} H_{2 a}} & =1 \\
H_{1 a}+H_{2 a} & =h_{a}
\end{aligned}
$$

where the subscript $a$ denotes either $s$ for the sill or $c$ for the contraction where these conditions are both specified. These equations are further complemented by

$$
\begin{gathered}
u_{1 c} H_{1 c} B_{1 c}=u_{1 s} H_{1 s} B_{1 s} \\
u_{2 c} H_{2 c} B_{2 c}=u_{2 s} H_{2 s} B_{2 s} \\
u_{1 s} H_{1 s} B_{1 s}+u_{2 s} H_{2 s} B_{2 s}=q_{0}
\end{gathered}
$$

$$
\frac{1}{2}\left(u_{1 s}^{2}-u_{2 s}^{2}\right)+g H_{1 s}=\frac{1}{2}\left(u_{1 c}^{2}-u_{2 c}^{2}\right)+g^{\prime} H_{1 c} .
$$

Therefore, given the geometry of the strait at the control sections (i.e., $h_{s}, h_{c}, B_{1 s}, B_{2 s}, B_{1 c}, B_{2 c}$ ), the densities of the layers leading to the specification of the reduced gravity $g^{\prime}=g\left(1-\rho_{1} / \rho_{2}\right)$, and the net barotropic flow $q_{0}$, the internal hydraulic theory of FA provides the interface positions at the control sections $\left(H_{1 s}, H_{2 s}\right.$, $\left.H_{1 c}, H_{2 c}\right)$ and the currents in the layers $\left(u_{1 s}, u_{2 s}\right.$, $\left.u_{1 c}, u_{2 c}\right)$.

For the given values of the input parameters specified in Table 2, the computed layer transports as a function of $q_{0}$ for different set of the width values are shown in Fig. 10. The $q_{1}$ and $-q_{2}$ curves numbered 1 correspond to the case having similar width values employed in the numerical model computations. Comparing the results with those shown in Fig. 9, it may be noted that the analytical model generally tends to overpredict the flow rates in the layers. Since the numerical model results have already indicated that a reduction in friction tends to strengthen the layer transports, the prediction of higher flow rates by the analytical model is to be expected. However, the difference between numerically and analytically obtained results becomes progressively larger for increasing values of $q_{0}$, owing to the nonlinear dependence of the layer transports on the net barotropic flow. For example, the blockage of the lower layer, in which $q_{2}=0$ at the sill crest, occurs when $q_{0} \approx 26000 \mathrm{~m}^{3} \mathrm{~s}^{-1}$ in the numerical model whereas the FA analysis provides the same condition for $q_{0} \approx 46000 \mathrm{~m}^{3} \mathrm{~s}^{-1}$.

As also pointed out by Farmer and Armi (1986), the model results are quite sensitive to the width vari-

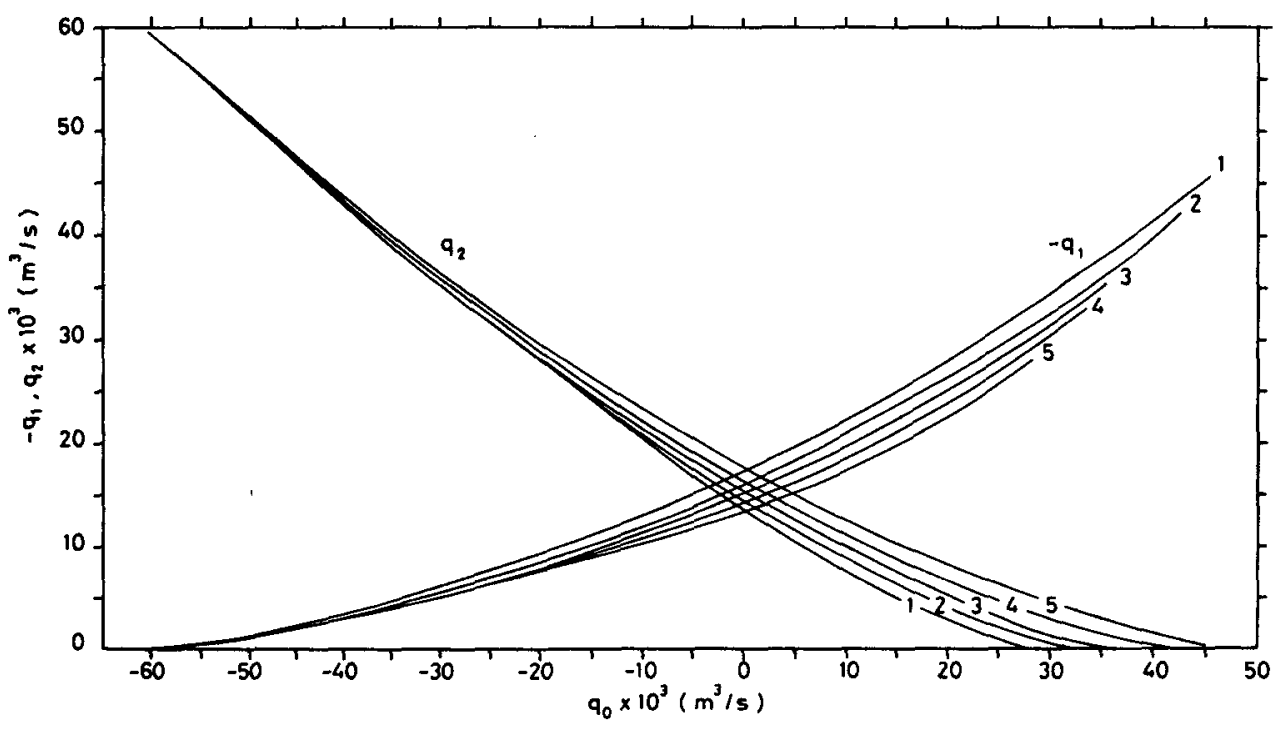

FIG. 10. Upper and lower layer transports $\left(-q_{1}, q_{2}\right)$ versus $q_{0}$ obtained by the analytic model. 
ations. This is shown in Fig. 10 by the curves numbered from 2 to 5 corresponding to the different set of width specifications at the narrowest section. It is clear that reducing the widths of the layers at the constriction tends to decrease the layer transports. The case with $B_{1 c}=B_{2 c}=325 \mathrm{~m}$, shown by curve 5 , gives flow rates similar to those predicted by the numerical model, shown in Fig. 9. The choice of typical values of the channel widths at the sill crest used in the numerical model computations, $B_{1 s} \approx \mathrm{O}(3000-3500 \mathrm{~m})$ for the upper layer and $B_{2 s} \approx \mathrm{O}(400-600 \mathrm{~m})$ for the lower layer, provides further modifications in the flow rates.

Figure 10 also includes the cases with northerly flowing net barotropic flow due to a higher rate of underflow. As pointed out in section 2, this case may possibly arise in the Bosphorus during weak upperlayer flow conditions subject to the pronounced southerlies observed in winter. The upper layer at the narrowest section is arrested, irrespective of the widths specified for the layers at the control sections, for considerably high values of the lower layer transport with $q_{2} \approx 65000 \mathrm{~m}^{3} \mathrm{~s}^{-1}$.

\section{Summary and conclusions}

Recent hydrographic observations obtained in the Bosphorus Strait illustrate several features of the flow that may be related to the internal hydraulics. The asymmetric forms of the interface depth, indicated by the distribution of isohalines in the salinity transects, imply a series of internal hydraulic adjustments of the flow by features such as sills, the bottom topography, and contraction and abrupt expansion of the channel width.

The anticipated hydraulic conditions in the strait are analyzed by a two-layer, laterally averaged numerical model. The computed profiles of the interface depth and the salinities in each layer are found to be in accord with the observed flow structure inferred by the salinity transects. It has been shown that the strait possesses three distinct regions of supercritical flow as anticipated in the hydrographic surveys. The lower layer water of the Marmara Sea origin flows north in a progressively thinning layer and is eventually controlled by the sill found immediately outside the Black Sea extremity of the strait. The upper layer water of Black Sea origin flows in the opposite direction and is controlled upon reaching the constricted region and near the abruptly widening southern extremity of the strait. The supercritical region of the latter control starts in the southern sill region and extends up to the Marmara exit region, comprising a distance of about $5 \mathrm{~km}$. The controls exerted by the northern sill and the contraction are separated by a subcritical region whereas the supercritical conditions downstream of these controls isolate the two-way exchange from conditions in the adjacent regions. In this way, the requirement for the maximal exchange is met implying that the Bosphorus achieves the maximum possible transports in the layers depending on the net barotropic transport through the strait. The form of exchange may, therefore, be fully governed by conditions within the strait and not dictated by conditions in the adjacent basins. Depending on the average densities of the layers, the geometry and the magnitude of net barotropic flow passing through the strait, the critical controls may determine the magnitudes of flows in the layers and the shape of the interface established in the channel.

The model computations always result in critical controls at the northern sill and the abruptly widening Marmara exit regions. Presence of a control at the constricted region, however, depends on the magnitude of the net barotropic flow passing through the strait. It is found that the control at the narrowest section may be lost for sufficiently weak upper layer flow. In this case, the maximal exchange takes place by the pair of controls exercised at the northern sill and the southern end.

The computed distributions of layer-average salinities show how the mixing and stratification characteristics along the strait may be influenced by the internal hydraulic adjustment of the exchange flow. The largest changes in the transports and salinities are found to occur in regions of the supercritical flow associated with the hydraulic controls. In the region downstream of the northern control, some of the upper layer water of the Black Sea is entrained into the lower layer and carried back to the sea of origin. In the constricted region, the interfacial exchange may be significant only when there exists sufficiently large net barotropic flow through the strait. The most drastic changes in the transports and salinities take place at the southern exit region where the channel expands abruptly to the Marmara Sea. The model computations show that almost half of the lower layer flow coming into the region from the eastern Marmara basin is lost by entrainment into the upper layer. Consequently, the upper layer salinity prescribed as $18 \mathrm{ppt}$ at the Black Sea termination of the strait increases typically to $23-25$ ppt at the southern exit region. The lower layer salinity of $38 \mathrm{ppt}$ at the Marmara end of the strait, on the other hand, may decrease up to $33 \mathrm{ppt}$ at the northern sill region showing that the Mediterranean effluent is diluted to a considerable extent before it joins into the western Black Sea.

The model computations reveal vanishing lower layer transport in the strait when the net barotropic flow becomes about $26000 \mathrm{~m}^{3} \mathrm{~s}^{-1}$ in which case the maximum difference between the surface elevations at both ends is approximately $45 \mathrm{~cm}$. In the case of vanishing net barotropic flow, however, the elevation difference reduces to about $18 \mathrm{~cm}$ and the transports in both layers are about $13000 \mathrm{~m}^{3} \mathrm{~s}^{-1}$, on the average. These values are subject to some changes depending on the values of friction coefficients adopted in the 


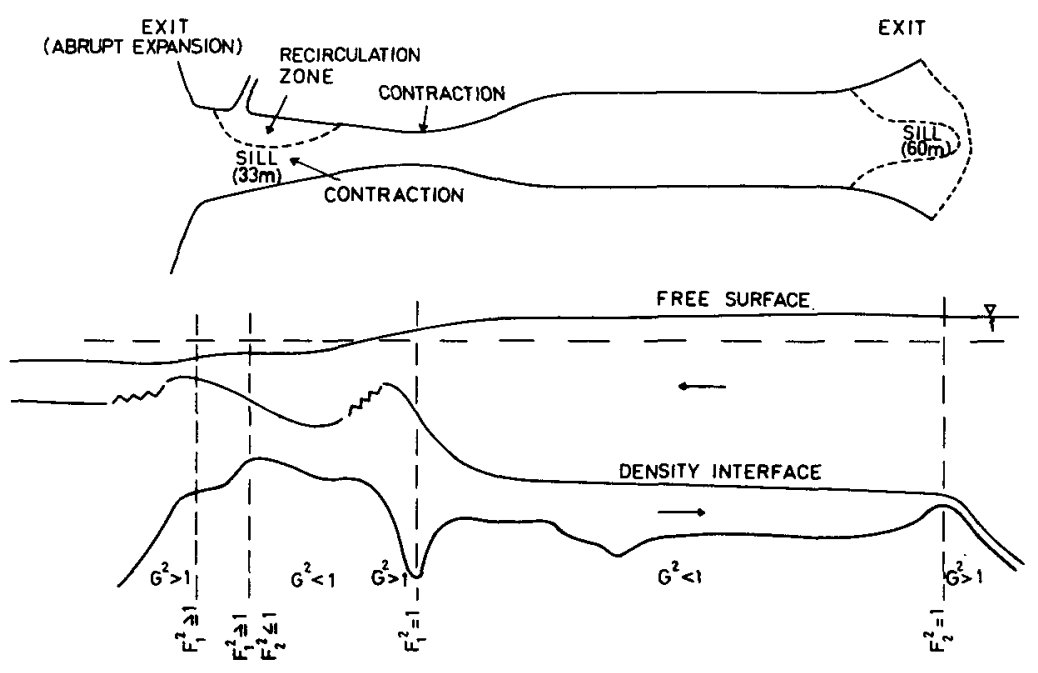

FIG. 11. Schematic picture of the Bosphorus internal hydraulics.

computations. In general, the computed values of transport rates and elevation differences are consistent with those reported in earlier studies (cf. Tolmazin 1985; Özsoy et al. 1986).

The flows in the layers computed by the numerical model turn out to be smaller as compared to those provided by the FA analytical approach. The difference tends to become larger for increasing values of the net barotropic flow. The analytical model results are also sensitive to the values of widths specified at the sill crest and the constriction. The changes $\mathrm{O}(100 \mathrm{~m})$ may apparently yield substantial changes in the resulting flow rates. In the case of northerly flowing net barotropic flow, the upper layer is arrested at the constriction, irrespective of the width specifications, for considerably large values of the lower layer transport, corresponding to $q_{2} \approx 65000 \mathrm{~m}^{3} \mathrm{~s}^{-1}$.

The two-layer model described in this paper explains successfully the basic features of the quasi-steady flow structure and associated mixing and stratification characteristics in terms of internal hydraulics of the exchange flow. A summary of the main elements of the Bosphorus internal hydraulics, which emerge from both observations and the numerical model studies, are schematically depicted in Fig. 11.

The two layer idealization of the flow structure has a deficiency that the hypothetical control over the southern sill can not be resolved properly by the model. Near the southern end of the strait, due to the intense vertical mixing, the surface and bottom layers are separated by a relatively broad interfacial layer. A three layer extension of the present model, which incorporates the transitional layer separately and therefore leads to a better approximation of the bottom layer, is necessary to simulate the possible control at the southern sill.
Acknowledgments. This work was partially supported by the Greater City of Istanbul Water and Sewerage Administration.

\section{REFERENCES}

Abbott, M. B., H. Schroder and I. R. Warren, 1978: Modelling of the salinity intrusion in the Sound between Denmark and Sweden. Proc. Int. Conf. on Water Resources Engineering, Bangkok, 195-207.

Armi, L., and D. M. Farmer, 1987: A generalization of the concept of maximal exchange in a strait. J. Geophys. Res., 92, 14 67914680 .

$\longrightarrow$, and — 1988: The flow of Mediterranean water through the Strait of Gibraltar. Progress in Oceanography, Vol. 21, Pergamon, 1-105.

Assaf, G., and A. Hecht, 1974: Sea-straits: A dynamical model. DeepSea Res., 21, 947-958.

Balloffet, A., and D. Borah, 1985: Lower Mississippi salinity analysis. J. Hydrol. Div. ASCE, 111, 300-315.

Bush, E., 1981: On the entrainment and vertical mixing in stably stratified fjords. Estuar. Coastal Mar. Sci., 12, 461-469.

Büyükay, M., 1989: The surface and internal oscillations in the Bosphorus, related to meteorological forces. M.S. thesis, Inst. of Mar. Sci., Middle East Technical University, $169 \mathrm{pp}$.

Christodoulou, G. C., and J. J. Connor, 1980: Dispersion in twolayer stratified water bodies. J. Hydraul. Div. ASCE, 106, 557573.

Çeçen, K., M. Beyazit, M. Sümer, Ş. Güçlüer, M. Doğusal and H. Yüce, 1981: Oceanographic and hydraulic investigation of the Bosphorus. Final Report, submitted to the Irrigation Unit of the Turkish Scientific and Technical Research Council, Istanbul Technical University, $166 \mathrm{pp}$. (in Turkish).

De Filippi, G. L., L. Iovenitti and A. Akyarli, 1986: Current analysis in the Sea of Marmara-Bosphorus junction. First AIOM Congress, Venice.

Farmer, D. M., and H. J. Freeland, 1983: The physical oceanography of f jords. Progress in Oceanography, Vol. 12, Pergamon, 147220.

sill in Observatory inlet. J. Geophy. Res., 90, 9051-9068.

, and L. Armi, 1986: Maximal two-layer exchange over a sill 
and through the combination of a sill and contraction with barotropic flow. J. Fluid Mech., 164, 53-76.

- , and -1988 : The flow of Atlantic water through the Strait of Gibraltar. Progress in Oceanography, Vol. 21, Pergamon, 1105.

Grubert, J. P., and M. B. Abbott, 1972: Numerical computation of stratified nearly horizontal flows. J. Hydr. Div. ASCE, HY10, $1847-1863$.

Gunnerson, C. G., and E. Ozturgut, 1974: The Bosphorus. The Black Sea Geology, Chemistry and Biology, Memoir 20. E. T. Degens and D. A. Ross, Eds., Am. Assoc. Pet. Geol., 249-278.

Hodgins, H. O., 1979: A time dependent two-layer model of f jord circulation and its application to Albeni Inlet, British Columbia. Estuar. Coastal Mar. Sci., 8, 361-378.

Kantha, L., 1985: Comments on "On tidal motion in a stratified inlet, with particular reference to boundary conditions." J. Phys. Oceanogr., 15, 1608-1609.

Krauss, E. B., 1977: Modelling and Prediction of the Upper Layers of the Ocean. Pergamon Press, $325 \mathrm{pp}$.

Kranenburg, C., 1987: Boundary-induced entrainment in two-layer stratified flow. J. Geophys. Res., 92, 5417-5425.

Kullenberg, G., 1977: Entrainment velocity in natural stratified shear flow. Estuar. Coastal Mar. Sci., 5, 329-338.

Latif, M. A., E. Özsoy, T. Oğuz and Ü. Ünlüata, 1988: Oceanographic characteristics of the region surrounding the northern entrance of the Bosphorus as related to the planned sewage outfalls. First Annual Rep. Institute of Marine Sciences, Middle East Technical University, $111 \mathrm{pp}$.

,$--\frac{1}{-}$ and -1990 : Observations of the Mediterranean effluent in the Bosphorus-Black Sea junction region. Deep-Sea Res., in press.

La Violette, P. E., and R. A. Arnone, 1988: A tide-generated internal waveform in the western approaches to the Strait of Gibraltar. J. Geophy. Res., 93, 15 653-15 667.

Moller, J. S., and F. B. Pedersen, 1983: Internal seiches in a stratified sill fjord. Inst. Hydrodynamics and Hydraulic Engineering, Technical University of Denmark. Progress Rep., No. 58, 31 40.

Oğuz, T., and H. İ. Sur, 1989: A two-layer model of water exchange through the Dardanelles Strait. Oceanol. Acta, 12, 23-31.

—, M. A. Latif, H. I. Sur, E. Özsoy and U. Ümit, 1989: On the dynamics of the Southern Black Sea. The Black Sea Oceanog. raphy, E. Izdar, J. Murray, Eds., appears in NATO/ASI Series. Kluwer, Academic, in press.
Özsoy, E., T. Oğuz, M. A. Latif and Ü. Ünlüata, 1986: Oceanography of the Turkish Straits. First Annual Rep., Institute of Marine Sciences, Middle East Technical University, Vol. 1, 269 pp.

,,,,---- H. I. Sur and Ş. Beşiktepe, 1988: Oceanography of the Turkish Straits. Second Annual Rep. Institute of Marine Sciences, Middle East Technical University, Vol. 2, $269 \mathrm{pp}$.

Pearson, C. E., and D. F. Winter, 1984: On tidal motion in a stratified inlet, with particular reference to boundary conditions. J. Phys. Oceanogr., 14, 1307-1314.

Pedersen, F. B., 1980: A monograph on turbulent entrainment and friction in two-layer stratified flow. Inst. Hydrodynamics and Hydraulic Engineering, Technical University Denmark, Ser. Pap. No. 25, 397 pp.

Pratt, L. J., 1986: Hydraulic control of sill flow with bottom friction. J. Phys. Oceanogr., 16, 1970-1980.

Stacey, M. W., and L. J. Zedel, 1986: The time-dependent hydraulic flow and dissipation over the sill of observatory inlet. J. Phys. Oceanogr., 16, 1062-1076.

Stigebrant, A., 1981: A mechanism governing the estuarine circulation in deep, strongly stratified fjords. Estuarine Coastal Shelf Sci., 13, 197-211.

Sur, H. I., 1988: Numerical modelling studies of two-layer flows in the Dardanelles Strait and the Bay of Izmit. Ph.D. thesis, Institute of Mar. Sci., Middle East Technical University, 245 pp.

Sümer, M., and M. Bakioğlu, 1981: Sea-strait flow with special reference to Bosphorus. Tech. Rep., Faculty of Civil Engineering, Technical University of İstanbul, $25 \mathrm{pp}$.

Thompson, J. D., 1974: The coastal upwelling cycle on the betaplane hydrodynamics and thermodynamics. Techn. Rep., Florida State University, Mesoscale Air-Sea Interaction Group, 141 pp.

Tolmazin, D., 1985: Changing coastal oceanography of the Black Sea. Part II: Mediterranean effluent, Progress in Oceanography, Vol. 15, 277-316.

Ünlüata, Ü., and T. Oğuz, 1983: A review of the dynamical aspects of the Bosphorus. On Atmospheric and Oceanographic Circulation of the Mediterranean. $\mathrm{H}$. Charnok, Ed., in press.

- - - M. A. Latif and E. Özsoy, 1990: On the physical oceanography of the Turkish Straits. The Physical Oceanography of Sea Straits, L. J. Pratt, Ed., NATO/ASI Series. Kluwer.

Wang, D. P., 1987: Strait surface outflow. J. Geophy. Res., 92, $10807-$ 10825 . 